\title{
Social and Ecological Drivers of the Economic Value of Pollination Services Delivered to Coffee in Central Uganda
}

\author{
Bin Mushambanyi Théodore Munyuli ${ }^{1,2,3,4}$ \\ ${ }^{1}$ Department of Environmental and Natural Resource Economics, Faculty of Natural Resources and Environmental sciences, \\ Namasagali Campus, Busitema University, P.O. Box 236, Tororo, Uganda \\ ${ }^{2}$ Départements de Biologie et Environnement, Centre National de Recherche en Sciences Naturelles (CRSN/Lwiro), D.S. Bukavu, \\ Sud-Kivu, Democratic Republic of Congo \\ ${ }^{3}$ Département de Nutrition and Diététique, Centre de Recherche pour la Promotion de la Santé (CRPS), \\ Institut Supérieur des Techniques Médicales, ISTM Bukavu, P.O. Box 3036, Sud-Kivu, Democratic Republic of Congo \\ ${ }^{4}$ Faculté des Sciences Environnementales, Gestion des Ressources Naturelles, Conservation de la Nature et Tourisme, \\ Université du Cinquantenaire de Lwiro (UNIC/Lwiro), D.S. Bukavu, Kivu, Democratic Republic of Congo
}

Correspondence should be addressed to Bin Mushambanyi Théodore Munyuli; tmunyuli@gmail.com

Received 10 September 2013; Revised 19 November 2013; Accepted 6 December 2013; Published 2 March 2014

Academic Editor: Ernesto I. Badano

Copyright (C) 2014 Bin Mushambanyi Théodore Munyuli. This is an open access article distributed under the Creative Commons Attribution License, which permits unrestricted use, distribution, and reproduction in any medium, provided the original work is properly cited.

\begin{abstract}
On-farm pollination experiments were conducted in 30 different small-scale coffee fields to determine monetary value attributable to pollination services in coffee production and to identify the degree of influences of various socio-ecological drivers in Uganda. Ecological-economic approaches were applied to determine the economic value of pollinating services. Economic value of bees increased significantly with increase in coffee farm size, bee diversity, and cover of seminatural habitats. The value of bees declined sharply $(P<0.05)$ with forest distance and cultivation intensity. Economic values of pollinating services associated with coffee fields established in regions with low intensity were found to be high. Organically managed small-scale coffee fields were 2 times more profitable than commercially managed farms. The annual value of pollinating services delivered by wild bees oscillated between US $\$ 67.18$ and US\$1431.36. Central Uganda produces in total 0.401 million tons of coffee beans for an approximate economic value of US\$214 million from which US\$149.42 million are attributable to pollination services. Policy makers should strengthen environmental/agricultural extension service systems to better serve farmers. Farmers are recommended to protect/increase the cover of natural and semi-natural habitats in the vicinity of their coffee fields to receive high economic benefits from pollinating services delivered by bees.
\end{abstract}

\section{Introduction}

In rural areas of sub-Saharan Africa including Uganda, most people depend on various ecosystem services (crop pollination, biological pest control, nutrient cycling, hydrological services, etc.) delivered in and from agricultural systems [1]. Crop productivity is improved by ecosystem services, including pollination, but this should be set in the context of trade-offs among multiple management practices [2]. Ecosystem services in agricultural systems are shaped by the coupling of management interventions and environmental variables [2].
Coffee (Coffea arabica and C. robusta) is one of the world important crops that benefit from animal pollination. It is the second most traded global commodity by developing nations after oil [3-5]. Coffee is cultivated in many parts of the world's most biodiverse regions [5-7].

The crop makes up a large percentage of total agricultural export revenue in countries like Mexico, Peru, Brazil, Indonesia, Ecuador, Costa Rica, Ghana, Uganda, Cameroon, Cote d'Ivoire, Rwanda, Burundi, Kenya, and DR Congo. In Uganda, coffee is an important cash crop; it plays a central role in the economy of the country. Thus coffee provides a major source of foreign exchange, as well as supporting 
the livelihoods of millions of rural families. At the farmer level, coffee remains an important source of income since its production accounts for over $50 \%$ of total income of the small-scale farmer. Coffee is the largest agricultural foreign revenue earner in Uganda. Coffee accounts for more than $58 \%$ of the total export earnings. From the exports of coffee, the government of Uganda earned \$US 389 million in 2009 $[8,9]$. Consequently, coffee holds a prominent position as a cash/industrial crop in Uganda's economy. Despite the pivotal role played by coffee in the economy, factors driving its production increase remain largely unsurveyed in Uganda.

Since 2005, the government of Uganda has been encouraging initiatives to increase the productivity of coffee at the farmer level across all production zones of the country [9]. However, such improvements need an understanding of factors determining yield increase and stability of coffee in Uganda. Several production factors of coffee are known by agronomists, such as soil nutrients and moisture contents, integrated pest management, and improved/resistant varieties, but the role of pollinators is quiet often not explored by agriculturalists.

Currently, major factors contributing significantly to yield increase and or stability of coffee in Uganda are not known, although there are lines of evidence indicating that coffee benefits a lot from animal pollination to set fruit [8-11]. However, this evidence is not enough to convince policy-makers to allocate resources for the conservation of pollinator biodiversity services in rural landscapes. Revealing the importance of pollinating services in monetary terms may be useful since human decision-making is mostly driven by financial considerations [8] particularly in sub-Saharan Africa. In Uganda, policy-makers are ready to listen if monetary values have been attached to a given ecosystem service that requires protection measurements to be taken. Although, it is very critical to economically value ecosystem services to influence decision-making, attaching a monetary value to a nature service that is not tradable is challenging. Knowledge of the value of pollination services is invaluable, and ascribing financial worth to them may help maintain pollinator biodiversity in agricultural landscapes in Uganda and in sub-Saharan Africa. The value of crop pollination can contribute significantly to decision-making when looking at the multiple benefits of conserving pollinator biodiversity in rural landscapes. Pollination services protection is thus a long-term investment that requires strong commitment by key stakeholders including farmers and leaders/decisionmakers in Uganda.

Therefore, it has been proven that pollinator services are important for coffee production [10-12], there is worldwide paucity of research about the economic value of pollination services in coffee production systems in relationship to various drivers [11, 13]. Some researchers have found that the economic value of coffee pollination services is driven by farm management systems, regional, landscape, and local drivers [14]. Integrated assessments of socioecological drivers are not yet published worldwide, but there is some data on the economic value of coffee pollination by bees $[6,12,13,15]$.

No previously published data are available for subSaharan Africa on economic value of coffee pollination from empirical experiments. In Uganda, neither the ecological importance nor the economic significance of pollination services delivered by bees to coffee has previously been studied empirically. There is therefore a need to determine the contribution of animal pollinators to coffee production. Intensive field experiments are thus required to collect information on the importance of pollinating services in coffee production $[6,12]$. Previous observations indicated that bees pollinate efficiently coffee flowers in Uganda $[8,9,16,17]$. However, the impacts of bees to coffee were not quantified in monetary terms.

This study deals with small-scale coffee farms that are pollinated by wild bee species, including wild honeybees (Apis mellifera), and it aims at determining the economic significance of pollination services in coffee production in Uganda and at identifing the level of influence of socioecological drivers of the variability of this economic value across study sites of different management/environment intensity gradients.

The specific objectives were (i) to determine economic value attributable to pollination services delivered by bees, (ii) to assess the influence of farm size on economic measures of coffee production (yield, revenue, profitability and value of bees), (iii) to examine the relationships between the economic measures of coffee production and landscape/regional drivers, and (iv) to determine the effects of farm extension, and local and regional land-use intensity gradients on economic measures of coffee production.

\section{Material and Methods}

2.1. Study Area. This study was conducted in the bananacoffee farming system of Lake Victoria Arc zone in central Uganda (Figure 1). The Lake Victoria crescent agroecological zone is characterized by ferrisoils with high to medium fertility level and receives on average $1000-1800 \mathrm{~mm}$ of rain on a bimodal pattern with $22-28^{\circ} \mathrm{C}$ and $60-75 \%$ of mean annual temperature and relative humidity, respectively $[18,19]$. Several food and cash crops that are pollinatordependent crops are grown in small-scale monoculture and or polyculture fields [8]. Robusta coffee (Coffea canephora) is the main cash crop and banana is the main staple food crop $[8,9,20]$.

Rural central Uganda is a mosaic landscape where "islands" of natural habitats (forest fragments, forest reserves, wetlands, and woodlands) are found scattered within agricultural matrices dominated by linear and nonlinear features of seminatural habitats (fallows, hedgerows, grasslands, forest plantations, and rangelands) that are displayed as field boundaries of diverse small-scale fields. Compared to other regions (districts) of Uganda, central Uganda is characterized by high demographic pressure, limited access to arable and fertile lands, intensive (continuous) crop cultivation and overexploited lands. However, the region has benefited much with some of the agricultural interventions (agricultural technologies dissemination) deployed by PMA (Plan for Modernization of Agriculture) actors and partners interested in socioeconomic transformation and sustainable development of the agricultural sector in Uganda. 


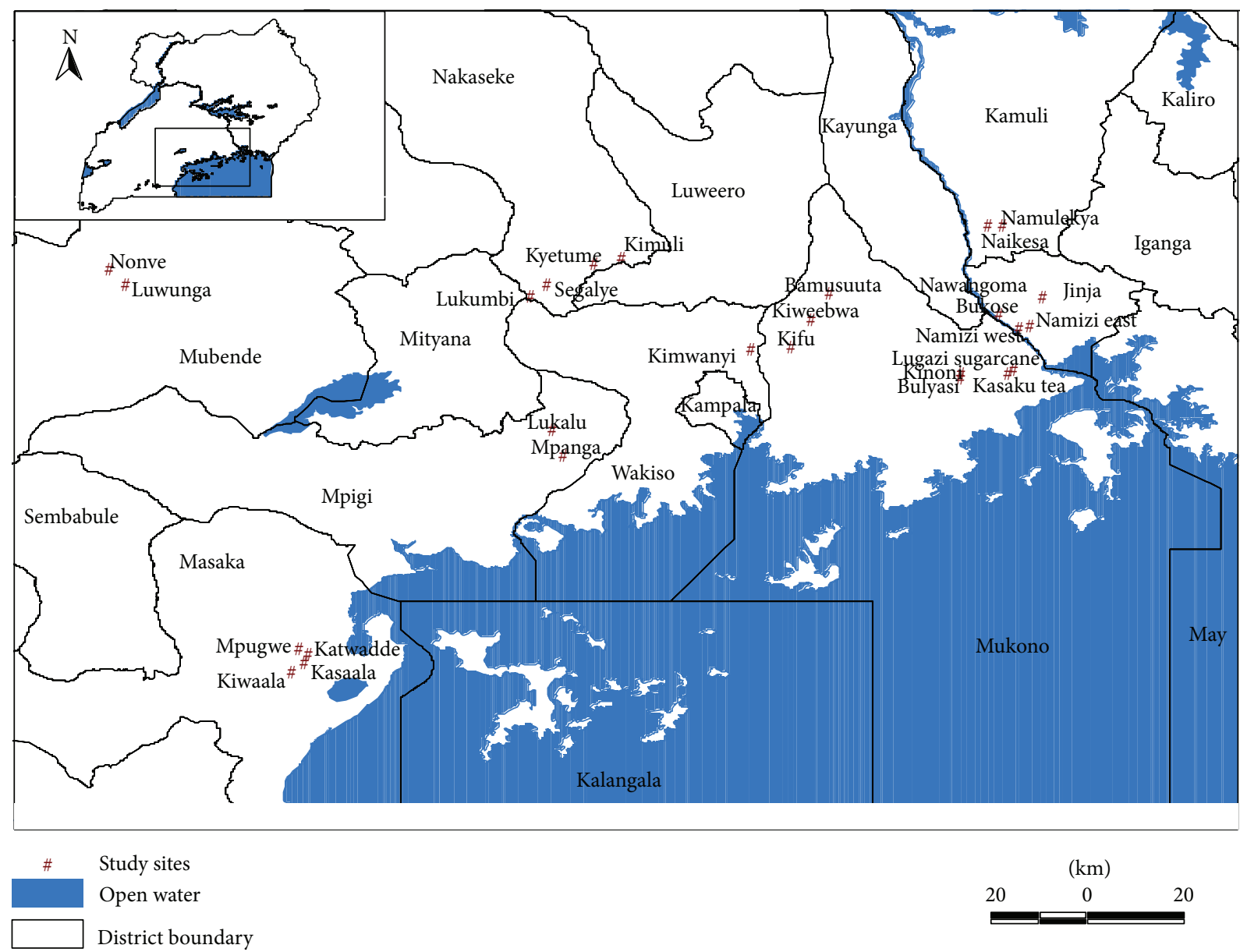

FIGURE 1: Location of study sites (per district) in which the coffee fields were selected in the banana-coffee growing area around Lake Victoria in central Uganda.

2.2. Selection of Experimental Coffee Fields. In collaboration with small farmers, pollination experiments were conducted in 30 different small-scale coffee farms $(0.25-15$ ha) that were selected from 26 different sites located in different districts in central Uganda (Figure 1). Details of criteria used to select the different study sites are presented in Munyuli $[9,21]$.

Fieldwork was conducted from June 1, 2007 to March 29, 2008 in the coffee-banana farming systems of central Uganda. Data were collected through conducting farmer surveys, through setting pollination experiments, and through field observations. Prior to the selection of experimental fields, a study tour of different sites was made and field characteristics were noted. Efforts were made to select at least one coffee field per study site $\left(1-\mathrm{km}^{2}\right)$, except for Lukalu, Mpanga, Kimuli, and Kifu sites from which more than one coffee field was selected per site. Each coffee field was selected at the centre of each square $\mathrm{km}$ within the study site. Coffee fields were 2 to $50 \mathrm{~km}$ apart from each other, which is beyond the maximum flight distance of large bees. Efforts were made to select coffee fields in areas where there were no managed bees (no hives with honeybees). In the region, colonies of honeybees (Apis mellifera adansonii and Apis mellifera scutelatta) are found both in hives and in the wild. Therefore, individual honeybees visiting coffee were assumed to come from wild colonies (feral colonies).

The 30 coffee fields were selected, for example, they are characterized by different vegetation, habitat, biotope, and land-use types found within and in the surroundings. They were also characterized by different farm management systems (organic, traditional, and commercial). Owners of the selected coffee fields receive advices from different agricultural extension services. In addition, the 30 coffee fields selected had coffee trees of almost the same ages (2-5 years). Different coffee varieties (genotypes) grown in mixture $(>2$ varieties mixed) or as sole (one variety grown) in each coffee field were recorded during field work.

In each of the 30 coffee fields, five trees were randomly selected. For each of these five trees, 3 branches with buds initiating flowers were also selected randomly. Experimental and control branches were tagged for visibility in the field during monitoring experiments. On each experimental branch, individual flowers were counted, labeled, and marked using colored ribbons [21]. In addition, the name of the variety (genotype) of every selected experimental coffee tree was recorded [8]. Details on procedures/methods followed to collect data on pollination experiments, coffee 
flower visitation intensities, richness, and abundance of bee species sampled are presented [22, 23]. After that, coffee pollination experiments were conducted using 3 pollination treatments: open pollination, cross-hand pollination, and insect-exclusion as recommended by Klein et al. [21] and Munyuli [16]. Results of the pollination experiments were used to measure different pollination services such as the proportion bee contribution to fruit set as recommended $[16,17]$.

Coffee fruit set was calculated as a proportion of total flowers that set fruit over the total number of flowers examined per experimental coffee branch. Based on three measures of pollination services delivery, the proportion potential yield of coffee (open pollination/cross-pollination), the proportion bee contribution to fruit set (open value obtained in open pollination treatment-value obtained in pollination exclusion cage treatment), and the proportion pollination limitation (cross pollination-open exclusion) were calculated $[8,17,21]$. These pollination service delivery measures were therefore calculated based on total and mean fruit set per treatment per coffee field.

The three measures (potential yield, bee contribution to fruit set, and pollination limitation) are classically calculated by pollination biologists to measure pollination services $[8,21,24,25]$. Practically, the proportion potential yield is the ratio of numbers of fruits set under open pollination conditions (full access of insects to flowers) and the hand cross pollination (manual fertilization of flowers). It indicates expected maximum yield if all other production factors are optimally available and if production constraints are minimized in coffee fields (e.g., no disease leading to fruit abortion). The proportion bee contribution to fruit set is the difference between fruit set under open pollination conditions and fruit set when all insects are denied access to flowers. It is a measure of the approximate contribution of bees to the fertilization of coffee flowers. The proportion pollination limitation is the difference between fruits after hand cross pollination (manual pollination) and fruits set after open pollination conditions (full access of insectpollinators to flowers). The proportion pollination limitation indicates what additional yield that can be obtained if the availability of different functional groups and efficient bee species in coffee fields is maximized from nearby natural and seminatural habitats.

2.3. Landscape and Regional Land-Use Intensity Variables. Data on landscape variables were collected within one$\mathrm{km}^{2}$ around each selected coffee field. Each $\mathrm{km}$ square was delineated using a GPS (Global Positioning System) such that the experimental coffee field was located at its centre. Because there was no previously published data on smallscale land-uses patterns in the study region, to facilitate basic measurements about different land-uses, the $\mathrm{km}^{2}$ area was divided into five transects of $200 \times 1000 \mathrm{~m}$. Here the area of different land-use types was measured using GPS, or a tape in case of small fields $(<50 \times 50 \mathrm{~m})$. Land-use types were grouped into major land-use types based on their size and frequency of occurrence in order to calculate the area covered by seminatural habitats, the area covered by crops, and the cover of dependent and nondependent cultivated crops per $\mathrm{km}^{2}$ area [26]. The term seminatural habitats included fallows, hedgerows, field margins, grasslands, roadsides, woodlands, woodlots, track-sides, stream-edges, and so forth. Pollinatordependent crops are those that require a visit to its flowers by a pollinator to set fruits/seeds $[8,9,26,27]$.

Three landscape variables of ecological importance $[8,9$, $25,27,28$ ] for pollination studies in agricultural matrices were then calculated for each coffee field: (i) The proportion (\%) of seminatural habitats, (ii) the cultivation intensity, that is, the percentage of the total land area cropped, and (iii) the distance from a given coffee field to the nearest potential natural pollinators' source (forest, wetlands). Distances up to $100 \mathrm{~m}$ were measured with a tape, otherwise with GPS (corrected to $\pm 1 \mathrm{~m}$ accuracy with Pathfinder v 2.0).

Regional land-use categories (low, medium, and high) were obtained from the Makerere University Geographic Information Service [25, 28]. Broad land-uses classified as low intensity use includes areas where at least three quarters of the land is uncultivated. Medium are managed habitat types where there is almost equal distribution of cultivated and uncultivated land. High are areas dominated by crops or livestock. Very high represents large monoculture estates of tea, sugar, coffee, and so forth. "For deeper descriptions of methods used to measure landscape and land-use intensity variables", see [16, 26-28].

\subsection{Agronomic Practices, Coffee Marketing, Farm Manage-} ment Intensity, and Coffee Genotypes. A total of 30 farmers, owners of the selected coffee fields, were interviewed using a semistructured questionnaire. Farmers were also provided with forms to record coffee yields. Survey questions were written in English but were translated into the main local language (Luganda) during interviews in order to facilitate farmers' understanding of the questions. All farmers were interviewed at their home $[8,9]$. Thereafter the researcher and the farmer visited the coffee farm in order to determine the total number of coffee trees in the field of the farmer, to record the farming and cultivation practices that were not reported by the farmer and verify some of the responses provided by the farmer. The total number of coffee trees in each field was determined by counting all coffee trees in the field. The survey generally sought farmers farming practices and marketing of coffee, coffee yield assessment, coffee production cost, and agricultural interventions and or extension services as described below.

To collect data on local farming practices and on coffee marking, farmers were asked to provide information on their experience (number of years) in coffee growing, shading regimes and shading tree plantation techniques applied, cultivation techniques, cultivated coffee genotypes (varieties), farm management system (traditional intensive, traditional extensive, commercial), farming practices such as application and type of pesticides and fertilizers, weed control techniques (hand-hoe versus herbicides), types of crops grown in association with coffee, existence of beekeeping activities in coffee fields, coffee yields (number of harvests per year, 
quantity harvested per harvesting season), harvesting and drying processes, packaging, and market price (farm gate price per $\mathrm{kg}$, price fluctuation over years). All prices were recorded in Uganda shillings and later converted to US\$. At the time of data collection, the exchange rate was lower than currently (during year 2007, US\$1 = 2100 Uganda shillings).

For the assessment of the coffee farm management intensity gradients, the 30 selected coffee fields were grouped into 3 management classes (levels/categories) based on farmers' survey "results and based on researchers" observation about the characteristics of the coffee farms (Table 1). Coffee management intensity characteristics were suspected to contribute to the variability of coffee yield and revenues [9], as it will be shown later. Farmers were also asked to report about the yields (as number and weight of sacks) of their harvested coffee beans per season. In order to validate the accuracy of the yield data from each farmer, the researcher randomly selected 5 coffee trees in each field for yield monitoring. Yields obtained from the 5 experimental coffee trees were used to extrapolate the potential yield of each coffee farm. The difference between the reported yield by farmers and the measured yield by the researcher was found to be statistically similar (paired $t$-test of mean difference: $T=0.96, P=0.69$, $N=30$ coffee fields). Therefore, harvests measured by the researcher and harvests reported by farmers during interview were used to obtain the average coffee yield data used during analysis.

2.5. Coffee Production Cost, Yield, and Revenue. Data were collected on both direct and indirect costs. The direct cost of production was considered as current variable costs [29]. The indirect costs of production included fixed costs such as the value of the land. Costs not reported by farmers were difficult to estimate and therefore were not considered in this study. For example, quite often, some farmers indicated that their family helped them in harvesting coffee berries, but it was difficult to know the number of sacs harvested by children or wives per day.

Farmers make two harvest periods per year: the first harvest is made from September to November and the second harvest is made from March to May. Coffee yield for every field was standardized into $\mathrm{kg} / \mathrm{ha}$ by dividing the total yield ( $\mathrm{kg}$ of dry coffee beans) per season by the area of the farm. In addition, coffee yield from each field was pooled across harvest seasons to obtain the yield per annum per farmer. The costs and revenues were calculated for each coffee field. The variable cost (VC), also called total cost of production [29], was calculated as the sum of all direct costs to coffee production. The total revenue (TR) (also referred to as gross revenue, total income, or gross margin) was calculated by multiplying the annual yield ( $\mathrm{kg} / \mathrm{ha}$ ) of dry un-processed coffee beans by farm gate price (price paid to the farmer at his home) that was variable across study sites. The net revenue (NR) or "profitability" was calculated by subtracting VC from TR. NR was used here as an index of profitability (economic return) of coffee production since it takes into account all annual operating expenditures and gross revenues of each coffee farmer.
During interview, each respondent was asked to provide detailed information about cost of coffee production at two levels: (i) coffee plant nutrition and health management and (ii) coffee harvest costs. Costs related to coffee plant nutrition and health management included: labour for planting shade trees, application of pesticides, mulching, weeding/pruning coffee; purchase of manure (cow dung) and fertilizers (synthetic, organic or green manure) and pesticides; and renting knapsack sprayers. Costs related to coffee berry harvests included: labour for harvesting coffee berries per harvest season, transport of coffee berries from the field to the farmers' home, and drying coffee berries. All costs were recorded in local currency (Uganda shillings) and later translated into US\$. Some farmers had almost no or low expenditures.

2.6. Identifying Agricultural Extension Service Providers Agencies. To detect the impacts of agricultural extension services providers on enhancing farmers' knowledge of managing farms to attract pollinators, data were collected on agricultural interventions scaled up under the plan for modernisation of agriculture (PMA) by different agricultural service providers. These interventions include agricultural advices (extension advices for coffee farmers; e.g., planting shading trees as resting sites for bees) delivered to farmers by various extension service agencies with a primary aim to improve crop/livestock productivity. During the interviews, farmers were asked to mention the type of extension advices (agriculture interventions) they had previously received and the name of the institution (extension agent) involved in delivery of such valuable services.

Because the interest was to identify extension service technical advices with potential impact on coffee production increase through the delivery of technical messages that may increase pollinators nearby coffee fields once implemented, farmers were asked to show evidence of the presence of different extension agents delivering vital agricultural advices to them. This was verified by the researcher through recording of sign posts of the agricultural extension institution within $1 \mathrm{~km}$ radius of the respondents coffee fields/home. In case the sign post was missing, the farmer and the researcher visited the person agent representing the advisory agent in the village (the village-based extension agent) to discuss and found out whether he has been teaching farmers some pollinator friendly farming/conservation techniques (e.g., planting optimal shading trees, organic farming, and conservation of seminatural habitats).

\subsection{Data Analysis}

2.7.1. Pollinator Dependency Determination. Fruit set was used as a measure of coffee pollination success. Thus, coffee fruit set was calculated as a proportion of the number of flowers that set fruit over the number of flowers examined during on-farm pollination experiments [17]. From the data of coffee fruit set, different pollination services measures (bee contribution to fruit set, pollination limitation, and proportion potential yield) were calculated following Munyuli [17]. Coffee dependency (the contribution of bees to coffee 
TABLE 1: Management systems of coffee in central Uganda.

Coffee farm management intensity systems (management intensity classes/categories)

Characteristics

Agroforestry shading trees the shade.

Extensive-traditional coffee fields Intensive-organic coffee fields

\begin{tabular}{ll}
\hline $\begin{array}{l}\text { Shade cover (\%) and } \\
\text { shading regimes }\end{array}$ & $\begin{array}{l}\text { Shaded coffee fields: } \\
>51-70 \% \text { shade cover }\end{array}$ \\
\hline Type of the coffee field & Small-scale coffee fields \\
\hline Farm management system & Traditional farms \\
\hline & $\begin{array}{l}\text { (i) Mixed natural shading trees } \\
\text { (ii) Traditional system fully } \\
\text { shaded and with rustic } \\
\text { management systems, where } \\
\text { dense native trees are associated } \\
\text { with coffee primarily to provide }\end{array}$
\end{tabular}

(iii) Coffee plantations are often located beneath the canopy of native and remnant tropical forest tree species and the vegetation in the lower strata is often not removed

Coffee plant size (height) Long to medium plant trees: 3-5 $\mathrm{m}$ height

(i) Generally set buds at 4 to 5

Age at harvest, productivity, years after plantation. and life span of trees

(ii) Coffee trees have a productivity life of $>30$ years

\begin{tabular}{ll}
\hline Coffee plant density & $\begin{array}{l}\text { Low density: } \\
100-1500 \text { coffee plants/ha }\end{array}$ \\
\hline Coffee yield (t/ha) & Low \\
\hline Coffee tree yield (Kg/tree) & High yield \\
\hline Quality of coffee bean & Higher \\
\hline $\begin{array}{l}\text { Application of } \\
\text { agrochemicals }\end{array}$ & $\begin{array}{l}\text { No use of chemical and organic } \\
\text { pesticides }\end{array}$
\end{tabular}

Pruning regime Light to no pruning regime

Seasonality in labour utilization

Seasonal labor utilization

Low air and soil temperature

Vegetation temperature

Litter production

Disease and pests incidence

High leaf litter
diseases and pests

Incidence of insect High incidence of insect pollinators pollinators

\section{Vegetation structural} complexity

Level of weed cover Low weed cover

Intercropping (polyculture/monoculture) systems
Coffee is intercropped with two

to five annual/biannual crops and with one perennial crop (banana)
Moderately shaded coffee fields: $>11-50 \%$ shade

Small-scale coffee fields

Organic farms

(i) Mixture of coffee with native shade tree species, plantations of diverse, and abundant indigenous

(agroforestry/apiary) tree species to provide shade to coffee.

(ii) More than 3-13 multipurpose tree species are associated with coffee trees and planted between rows of coffee trees at density of 50-200 stems/ha on average

Long to medium plant trees:

3-5 $\mathrm{m}$ height

Productivity of $10-20$ years

Moderated density: 500 to 1500 coffee plants/ha

High

Low to moderate yield

Medium

No use of artificial chemical pesticides but intensive use of organic or natural pesticides/fertilizers

Light pruning regime

Seasonal labor utilization

Low to moderated temperature of soils and vegetation

High leaf litter

Low to moderated incidence of diseases and pests

High incidence of insect pollinators

Complex

Low weed cover

(i) Integration of coffee production systems with beekeeping activities and with zero grazing to produce local

cow-dung and organic manures.

(ii) In most cases, coffee is mixed with Vanilla that uses coffee trees as stake since it is a climber crop species
Intensive-commercial coffee fields

Sunny coffee fields: $0-10 \%$ shade Small-scale fields Commercial farms

(i) Modern small-scale coffee farming systems characterized by coffee genotypes (cultivars) grown in sunny environments.

(ii) Shade tree species are associated with coffee trees at a density of 3-20 stems/ha planted at the boarder of the coffee farm.

(iii) In most case, there are no shade trees associated with coffee trees

Short size of coffee plant trees: 2-3 $\mathrm{m}$ height

(i) Age at the time of first harvest is 3-5 years.

(ii) Productivity of $10-20$ years

High density: 600-10000 coffee plants/ha

High

Moderated yield

Lower to higher

Intensive use of chemical pesticides/fertilizers

Heavy pruning systems

Year round and intensive use of labor

High air and soil temperatures

Low leaf litter

High to moderated incidence of disease and pests

Low to moderate incidence of pollinators

Low structural complexity

High weed cover

In rare cases, commercial coffee fields are mixed with two to three subsistence annual/subannual crop species 
TABle 1: Continued.

\begin{tabular}{|c|c|c|c|}
\hline \multirow[b]{2}{*}{ Characteristics } & \multicolumn{3}{|c|}{ Coffee farm management intensity systems (management intensity classes/categories) } \\
\hline & Extensive-traditional coffee fields & Intensive-organic coffee fields & $\begin{array}{l}\text { Intensive-commercial coffee } \\
\text { fields }\end{array}$ \\
\hline $\begin{array}{l}\text { Expected performance of } \\
\text { the coffee management } \\
\text { system }\end{array}$ & $\begin{array}{l}\text { Traditional coffee farms are likely } \\
\text { to contribute significantly to the } \\
\text { conservation of biodiversity in } \\
\text { farmlands of Uganda. However, } \\
\text { these coffee fields are generally } \\
\text { poorly managed. Farmers invest } \\
\text { less time in the production of } \\
\text { coffee. Farmers do no specific } \\
\text { management to improve the } \\
\text { coffee production. } \\
\text { Here, coffee is not the primary } \\
\text { objective of the producer but } \\
\text { probably coffee is cultivated to } \\
\text { produce additional cash to the } \\
\text { family }\end{array}$ & $\begin{array}{l}\text { Coffee is grown beneath the native forest } \\
\text { canopy together with several other crop } \\
\text { plant species for local subsistence (beans, } \\
\text { cassava, maize, sweet potatoes, bananas, } \\
\text { avocados, oranges, etc.). The system is } \\
\text { likely to enhance biodiversity in } \\
\text { agricultural landscapes since it is } \\
\text { managed intensively by using natural } \\
\text { products as inputs }\end{array}$ & $\begin{array}{l}\text { This system is almost a } \\
\text { small-scale intensive } \\
\text { monoculture system. Since } \\
\text { coffee is grown with a lot of } \\
\text { inputs, it is expected that yield } \\
\text { from this coffee production } \\
\text { system would be higher than } \\
\text { that in traditional and in } \\
\text { commercial systems }\end{array}$ \\
\hline
\end{tabular}

fruit set) values were obtained by subtracting the proportion fruit set of bagged flowers from the proportion fruit set when bees were allowed to visit coffee flowers. For each coffee field and during each coffee blooming season, coffee pollination dependency was determined by assessing bee contribution to fruit set [17] as PD $=($ FOP - FBT $) / F M C P$, where $\mathrm{PD}=$ coffee pollinator dependency; $\mathrm{FOP}=$ fruit set from open pollination treatment; FBT $=$ fruit set from exclusion pollination treatment, and FMCP = fruit set from hand cross-pollination treatment.

\subsubsection{Effects of Socioecological and Agronomic Drivers on} Economic Measures of Coffee Production. Multiple and simple linear regressions were used to explore the relationships between economic measures of coffee production (yield, revenue, profitability, and value of bees) and bee community variables (density and diversity) per coffee field. The relationships between the economic measures of coffee production and landscape drivers (forest distance, cultivation intensity, and \% cover of seminatural habitats) were determined using multiple and simple linear regressions. All independent variables such as bee community density and diversity or landscape drivers (forest distance, cultivation intensity and \% cover of seminatural habitats) were examined for collinearity $(r>0.70, P<0.001)$ prior to conducting regression analyses. Cultivation intensity and the percent cover of seminatural habitats were found to be collinear; thus, they were not entered in the same models during multiple regression analysis [17]. Multiple regression analyses were also conducted to evaluate the simultaneous effects of noncollinear explanatory variables on values of economic measures of coffee production (yield, revenue, profitability and value of bees). Differences between regression parameters were assessed with $t$-tests. Simple linear regression models were used to better illustrate significant relationships between independent (agro-socioecological drivers) and dependent variables (yield, revenue, profitability and value of bees) as predicted by multiple regressions analyses.
The multiple regression correlation coefficient $\left(R^{2}\right)$ was used as measure of amount of variability accounted for by the independent variables (forest distance/wetlands, \% seminatural habitats, been density, and bee diversity) for the dependent variables (yield, revenue, profitability, and value of bees) tested. The effects of agricultural services delivery on economics of coffee production measures were explored by applying a GLM analysis of variance with names of agencies recorded near the homestead of the farmer as fixed factors and the economics measures of coffee production as dependent variables. Simple linear regression models (using Minitab statistical package, version 15.1) were used to investigate the relationships between the farm size and the economics of coffee production (yield, revenue, profitability, and value of bees). General linear models (GLM) were used to determine the effects of farm management intensity systems (organic, traditional, and commercial), agronomic practices (cultivated coffee genotypes), and regional land-use intensity gradients (low, high, and medium levels) on the economic measures of coffee production (yield, gross revenue, net revenue, and value of pollination services) and on species richness and density of daily flower visiting bees.

Prior to analyses, all data were tested for normality and, if necessary, transformed. Back-transformed data are reported. Fisher's protected least significant difference (LSD) test for pairwise comparisons and means separation was applied as post hoc test when significant differences were indicated by the GLM procedure. All statistical analyses were conducted in Minitab English release version 15.

2.7.3. Measuring the Economic Value of Pollination Services. To determine economic value of pollination services delivered by bees to coffee, classical procedures developed by other workers were followed [15, 30-32]. The value of bees or the total economic value of pollinating services delivered to coffee by bees in each of the coffee fields was calculated by multiplying their coffee yields by local market prices of coffee beans (US\$ $/ \mathrm{kg}$ ) and by the pollination dependency factor. 
The overall mean economic value of pollinating services delivered by bees to coffee was determined using descriptive statistics (means, standard errors) in Minitab version 15.1 from two-season database of economic values obtained from each of the 30 coffee fields.

The total value generated by pollination services [30] to coffee farms (welfare to the famers) was also calculated with the following the equation: $W=S * \Delta q *(p-c)$, where $W$ $=$ welfare to coffee producer (US\$) or the producer surplus; $S$ = area under production (ha); $\Delta q=$ increase in productivity $(\mathrm{kg} / \mathrm{ha})$ as a consequence of pollination; $p=$ farm-gate price of the crop (US\$/kg); and $c=$ variable costs related to crop harvest (US\$ $/ \mathrm{kg})$.

\section{Results}

\subsection{Impacts of Social and Ecological Drivers}

3.1.1. Effects of Bee Communities. A high number of bee species were seen visiting coffee during the first and second blooming seasons. For information on the scientific names, abundance, and richness bee species visiting coffee flowers see Munyuli [17]. Bee diversity was found to be lower in unshaded coffee farming systems, but it progressively increased towards complex, shaded farming systems. The highest richness of pollinator species occurred in organic coffee fields followed by traditionally managed coffee fields, whereas the lowest species richness was frequently recorded in commercial coffee fields (Figure 2).

Coffee yield (kg/ha of dried coffee beans) was significantly related to both (i) richness of flower visiting wild bees (Figure 3(a)) and (ii) bee density per coffee tree (Figure 4(a)). The result suggested that an increase in coffee yield was a consequence of increase in the diversity and density of legitimate coffee pollinators. Hence, higher yield due to increased pollination services is likely to generate higher economic benefits (net revenues) per hectare. Gross revenue (US\$/ha/year) was positively related to bee diversity (Figure 3(b)) and to bee density (Figure 4(b)). This result suggested that a significant increase in the value of the annual gross revenue per hectare was possible with increasing number of flowervisiting bee species and individuals. In terms of impacts of bee communities on economic measures of coffee production, the above-mentioned relationships indicated that a fourfold increase in the density/diversity of bees was associated with a $300-450 \%$ increase in the gross revenue (US\$/ha/year).

The economic value of wild bees to coffee (US\$/ha/year) was positively related to both (i) bee diversity (Figure 3(c)) and (ii) bee abundance (Figure 4(c)), suggesting that the economic value of pollination services delivered by bees to coffee increased with an increase in the number of different bee species visiting coffee flowers, and with an increase in the number of bee individuals foraging on coffee flowers. These results indicated also that higher bee diversity and density led to higher economic value of bees to coffee. Overall, wild bee diversity explained $22 \%, 28 \%$ and $30 \%$ of the variation in coffee yield, gross revenue, and value of bees to coffee,

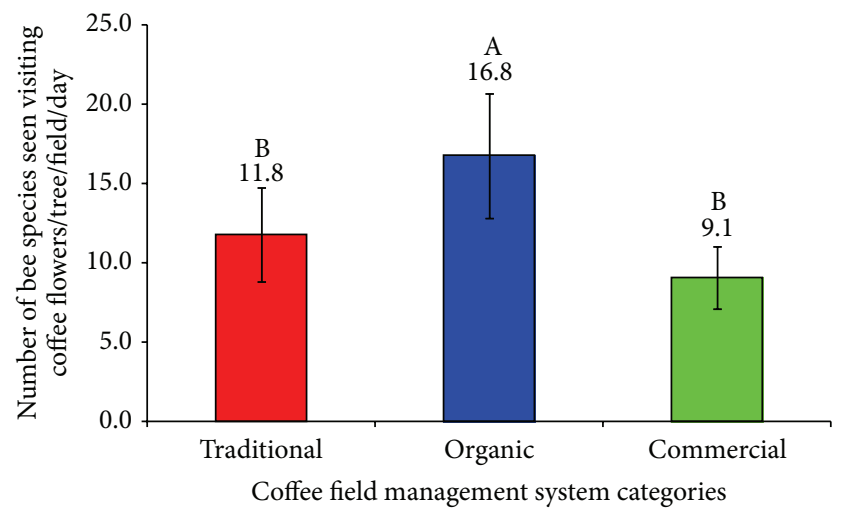

(a) [GLM-ANOVA: $F=3.89, P=0.017, \mathrm{DF}(2,28)]$

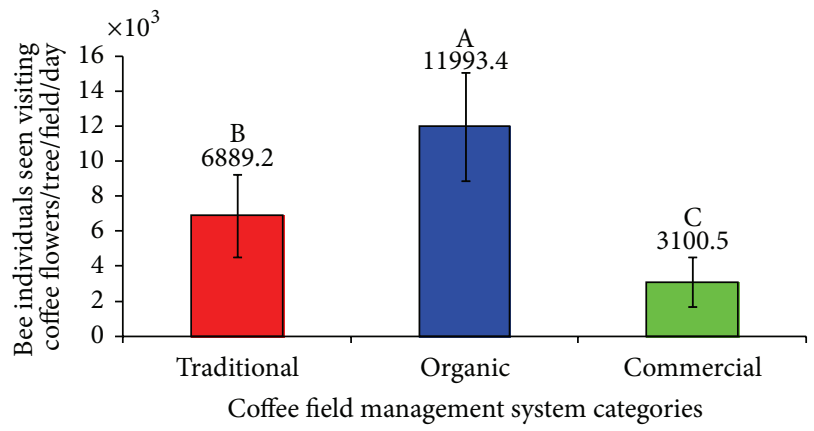

(b) [GLM-ANOVA: $F=12.82, P<0.001, \mathrm{DF}(2,28)]$

Figure 2: Daily richness (a) and density (b) of flower-visiting bee species (average number of bee species recorded visiting flowers, per coffee tree, each visitation counting day conducted in $180 \mathrm{~min}$ observations). Different letters above the bars indicate significant differences of means $(X \pm \mathrm{SE})$ between land-use categories at $P \leq$ 0.05. $P=$ statistical significance level; $(1,28)=$ value for degrees of freedom (DF); $F$ = analysis of variance value of Snedecor test; GLMANOVA = general linear model analysis of variance.

respectively (Figure 3). Additionally, bee abundance (density) accounted for $30 \%, 40 \%$, and $30 \%$ of the variation in coffee yield, gross revenue, and value of bees, respectively (Figure 4).

3.1.2. Effects of Agronomic and Farm Management Intensity Factors. There were significant (GLM test, $P<0.05$ ) effects of farm management intensity systems and cultivated coffee genotype types on coffee production economics. As suspected, farm management intensity (see characteristics of different management systems in Table 1$)$ had significant $(P<$ 0.05 ) effects on coffee yield, gross revenue, net revenue, and value of bees (Table 2) whereas cultivated coffee varieties had no significant effects $(P>0.05)$. However, agronomic (cultivated coffee varieties) and coffee farm management factors had significant $(P<0.05)$ effects on the direct cost of production (Table 2). Different coffee varieties were found being grown, either sole but most frequently in mixture, by small-scale coffee producers. These were (i) traditional varieties ("bush varieties"), (ii) "clonal coffee varieties" and Kawanda lines (1S/3, 1S/2, 1S/6, 258/24, 223/32). The different varieties found in the fields were confirmed by Dr Kyetere, 


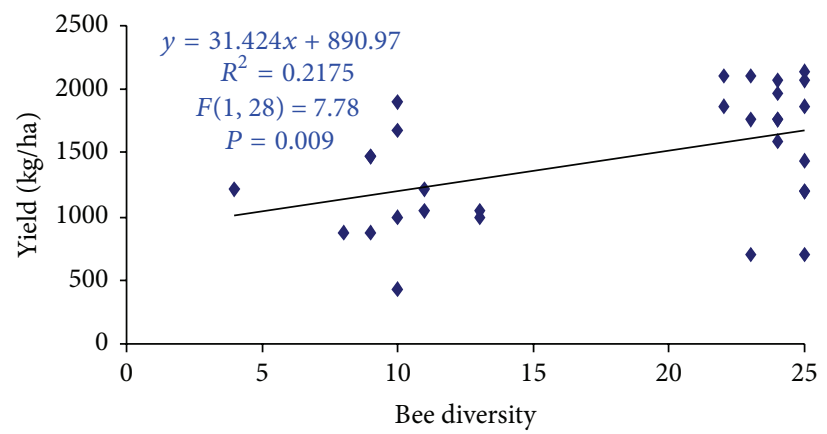

(a)

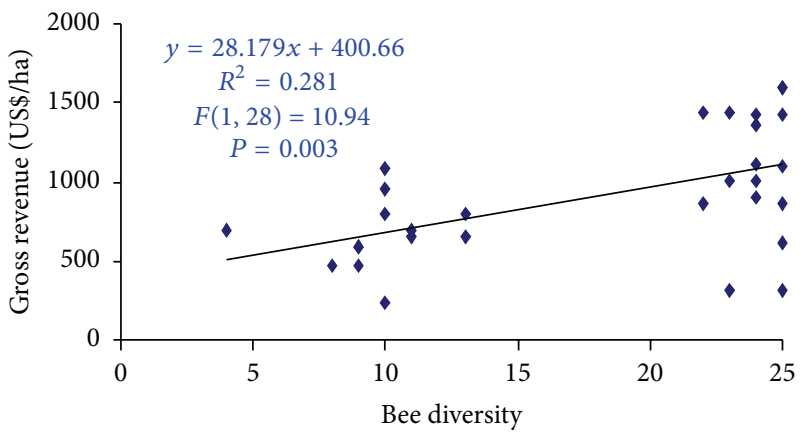

(b)

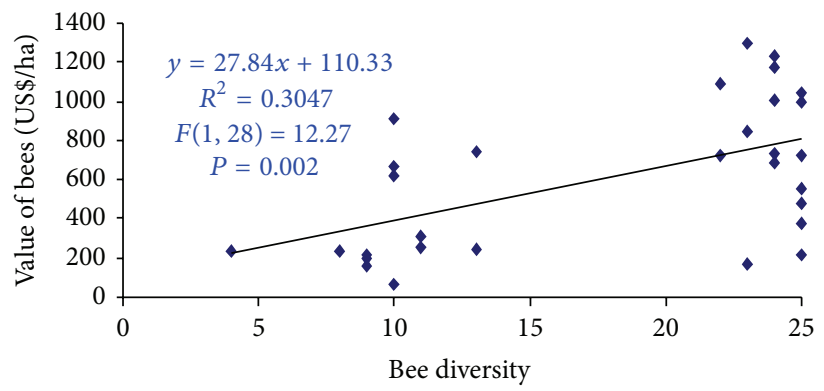

(c)

FIGURE 3: Relationships between bee diversity (number of bee species visiting coffee) and economic measures of coffee production: (a) Yield ( $\mathrm{kg} / \mathrm{ha}$ ); (b) gross revenue (US $\$ / \mathrm{ha}$ ), and (c) value of bees to coffee production (US\$ $/ \mathrm{ha}$ ). $R^{2}=$ coefficient of the determination of the regression model; SE = standard error; $P=$ statistical significance level; $(1,28)=$ degrees of freedom; $F=$ analysis of variance value of the Snedecor test.

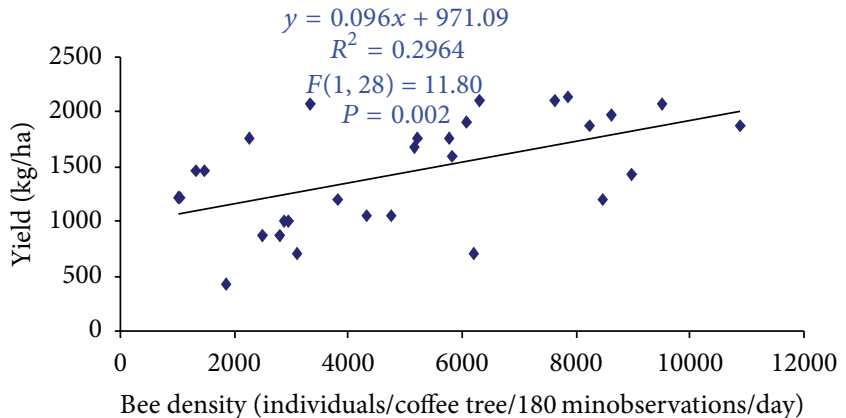

(a)

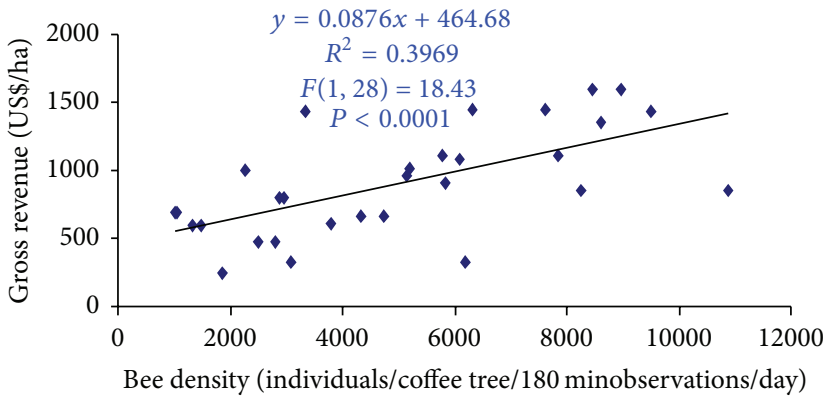

(b)

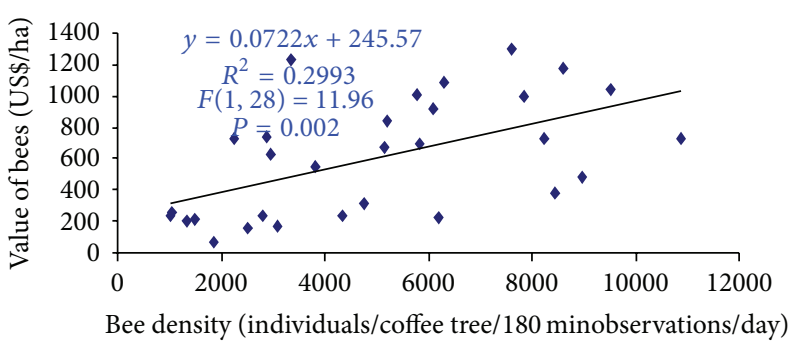

(c)

FIGURE 4: Relationship between the abundance of bees visiting coffee flowers economic measures of coffee production: (a) yield (kg/ha); (b) gross revenue (US $\$ / \mathrm{ha}$ ), and (c) the value of bees to coffee production (US $\$ / \mathrm{ha}) . R^{2}=$ coefficient of the determination of the regression model; $\mathrm{SE}=$ standard error; $P=$ statistical significance level $(1,28)=$ degrees of freedom; $F=$ analysis of variance value of Snedecor test. 
TABLE 2: Effects of coffee field management intensity, cultivated varieties, and agriculture interventions on economic measures of coffee production.

\begin{tabular}{|c|c|c|c|c|c|}
\hline Responses variables & Explanatory variables & Mean $(x \pm$ SE $)$ & d.f & $F$ value & $P$ value \\
\hline \multirow{4}{*}{ Yield (Kg coffee beans/ha) } & Coffee farm management intensity $(n=30)$ & & $(2,27)$ & 5.56 & 0.010 \\
\hline & Extensive-traditional farms ( $>51-70 \%$ shaded) & $1219.2 \pm 96.38^{\mathrm{b}}$ & & & \\
\hline & Intensive-commercial farms ( $0-10 \%$ shaded $)$ & $1926.0 \pm 53.53^{\mathrm{a}}$ & & & \\
\hline & Intensive-organic farms (11-50\% shaded) & $1805.2 \pm 120.8^{\mathrm{a}}$ & & & \\
\hline \multirow{4}{*}{ Gross revenue (US\$/ha) } & Coffee farm management intensity & & $(2,27)$ & 5.58 & 0.010 \\
\hline & Extensive-traditional farms ( $>51-70 \%$ shaded) & $731.51 \pm 52.84^{\mathrm{b}}$ & & & \\
\hline & Intensive-commercial farms ( $0-10 \%$ shaded $)$ & $1155.6 \pm 30.13^{\mathrm{a}}$ & & & \\
\hline & Intensive-organic farms (11-50\% shaded) & $1083.1 \pm 82.04^{\mathrm{a}}$ & & & \\
\hline \multirow{4}{*}{ Value of bees (US\$/ha) } & Coffee farm management intensity $(n=30)$ & & $(2,27)$ & 4.78 & 0.017 \\
\hline & Extensive-traditional farms ( $>51-70 \%$ shaded) & $421.6 \pm 30.41^{\mathrm{b}}$ & & & \\
\hline & Intensive-commercial farms ( $0-10 \%$ shaded $)$ & $939.5 \pm 86.64^{\mathrm{a}}$ & & & \\
\hline & Intensive-organic farms (11-50\% shaded) & $668.8 \pm 63.51^{\mathrm{a}}$ & & & \\
\hline \multirow{9}{*}{ Direct production cost (US\$/ha) } & Cultivated coffee varieties $(n=30)$ & & $(2,27)$ & 7.62 & 0.002 \\
\hline & Clonal varieties & $278.3 \pm 40.96^{\mathrm{a}}$ & & & \\
\hline & Mixture (traditional/clonal) varieties & $67.4 \pm 9.861^{\mathrm{b}}$ & & & \\
\hline & Traditional varieties (bush varieties) & $90.1 \pm 14.28^{\mathrm{b}}$ & & & \\
\hline & Agriculture services providers $(n=30)$ & & $(3,26)$ & 13.87 & 0.000 \\
\hline & APEP & $118.7 \pm 17.16^{\mathrm{a}}$ & & & \\
\hline & NAADS & $146.6 \pm 28.44^{\mathrm{a}}$ & & & \\
\hline & VI-AGROF & $137.6 \pm 24.44^{\mathrm{a}}$ & & & \\
\hline & NONE & $86.9 \pm 5.46^{b}$ & & & \\
\hline \multirow{4}{*}{ Net revenue (US\$/ha) } & Coffee farm management intensity $(n=30)$ & & $(2,27)$ & 3.17 & 0.038 \\
\hline & Extensive-traditional farms ( $>51-70 \%$ shaded) & $680.8 \pm 58.76^{\mathrm{b}}$ & & & \\
\hline & Intensive-commercial farms ( $0-10 \%$ shaded $)$ & $692.2 \pm 67.42^{\mathrm{b}}$ & & & \\
\hline & Intensive-organic farms (11-50\% shaded) & $998.4 \pm 48.92^{\mathrm{a}}$ & & & \\
\hline
\end{tabular}

Within columns, means followed by the same letters are not significantly different according to Fisher's protected least significant difference (LSD) test for mean separation at 5\% probability; US\$: United States of America dollars. APEP: agriculture productivity enhancement program of USAID-Uganda; NAADS: National Agriculture Advisory Services; VI-Agroforestry: Fifth-Agroforestry Project of the World Agroforestry Center in Uganda, NONE: no extension service institution was present in the study area.

a coffee breeder based at CORI (Coffee Research Institute of NARO-Uganda). All coffee varieties had similar pollination requirements.

In terms of impacts (\% increase/reduction in economic benefits) of management intensity systems, shaded coffee fields that were managed extensively (or managed as traditional farms) had a lower yield as compared to sunny commercial small-scale coffee fields that were intensively managed. Farmers who had intensive-commercial farms and intensive organic farms obtained $37 \%$ and $32 \%$ higher coffee yield than those who managed their coffee fields as extensive traditional farms (Table 2). In addition, small-scale coffee growers who had intensive-commercial farms and intensive-organic farms had $36.6 \%$ and $32.5 \%$ higher gross revenue, respectively, than those who managed their coffee fields as extensive traditional farms (Table 2). On average, the economic value of bees was 2 and 1.5 times higher in intensive-commercial farms and in intensive-organic farms than in extensive-traditional farms (Table 2). Thus, decreasing pollination services were likely to lead to low gross revenues, and this in turn may force coffee growers to reduce their costs by diminishing their management activities.
Overall, among the three farm management intensity categories, organic management system was found to be far away the best and most profitable coffee farm management system in central Uganda. The low profitability (economic return) in commercial farms and in traditional farms compared to organic farms (Table 2) is linked to heavy pesticides usage by farmers. None of the organic farmers had spent money or used agrochemicals on their farms, whereas more than $80 \%$ of commercial farmers used herbicides, insecticides, fungicides to control weeds, pests, and diseases in their coffee fields. Herbicides were applied at a regime of one spray per month across flower initiation, flowering, and berry maturing periods. Insecticides and fungicides were used to control coffee berry borers and other common coffee pests/diseases. Thus, commercial farms had higher production costs compared to traditional farms and to organic farms. High application of pesticides can erode bees, thus reducing fruit set of coffee.

3.1.3. Effects of Agricultural Extension Service Providers. Four categories of agriculture extension service provider agencies were identified in the study area. These included the following: (i) APEP: Agriculture Productivity Enhancement 


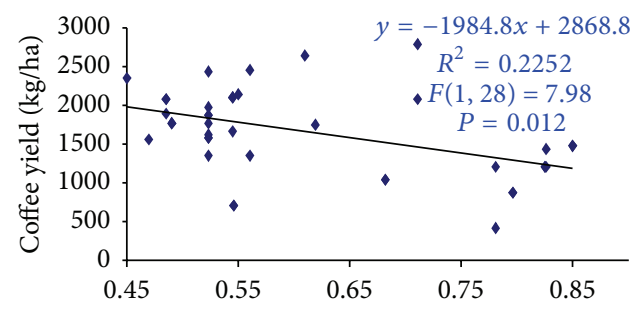

Proportion cultivation intensity $/ \mathrm{km}^{2}$ land area

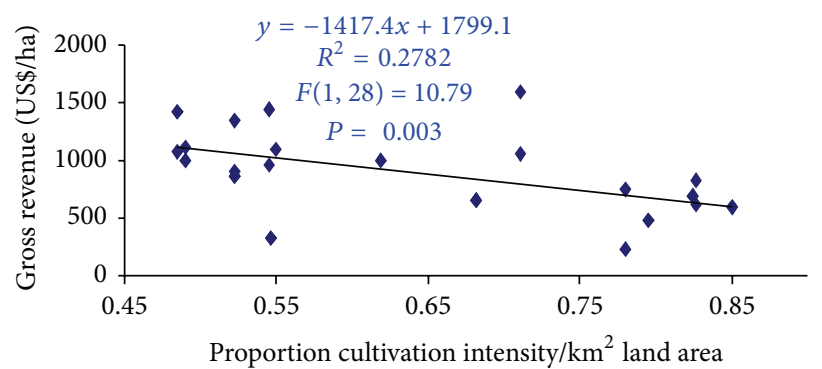

(b)

(a)

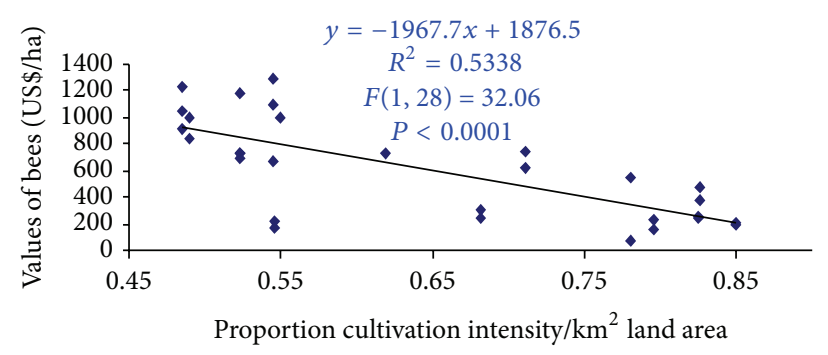

(c)

FIGURE 5: Relationships between the proportion cultivation intensity and economic measures of coffee production measures: (a) yield (kg/ha); (b) gross revenue (US\$/ha), and (c) the value of bees to coffee production (US $\$ /$ ha). $R^{2}=$ coefficient of the determination of the regression model; SE = standard error; $P=$ statistical significance level $(1,28)=$ degrees of freedom; $F=$ analysis of variance value of Snedecor test.

Program led by USAID-Uganda. APEP generally targets using demonstration-farms (advanced coffee farmers) to disseminate or scale up agricultural advices to increase coffee production in the region; extension workers of APEP teach coffee producers improved coffee farming methods: improved agronomic practices such as planting shading coffee trees, planting coffee wilt resistant varieties, shading/ pruning/weeding techniques, etc.); (ii) NAADS (the National Agriculture Advisory Services). NAADS was created under the plan for modernization of agriculture (PMA); this is government extension body mainly involved in delivery of critical extension messages through establishment of demonstration plots. NAADS aims at increasing crop productivity (e.g., coffee) at the farmer level; (iii) VI-Agroforestry: FifthAgroforestry project (VI-AGROF); this program aims at improving livelihood and agriculture productivity in rural areas through the dissemination of improvement agroforestry techniques such as the introduction/establishment of agroforestry/apiary/coffee shading tree species on farms; the project believes in trees-on farm to improve crop production, livelihoods and mitigate negative effects of climate changes; the program encourages farmers to conserve indigenous tree species on farm. Indigenous trees are potential nesting trees for various bee species; it is expected that strong establishment of agroforetry/apiary trees on farm is likely to attract a diversity of bee species within coffee fields; majority of introduced tree species were frequently seen in coffee fields during field visits although few of theses were used by bees as nesting sites; instead, bees visiting coffee flowers were observed emerging from nesting sites (e.g., termite mounds) established nearby fallows and hedgerows; (iv) NONE: no single extension service institution was present in the study area. Within the study area, some villages receive no advices (to improve their coffee farms) from extension service agencies.

The direct cost of production (US\$/ha/year) differed significantly $(P<0.05)$ among agricultural extension service providers. However, neither coffee yield, gross revenue, value of bees nor net revenue (profitability) were significantly $(P>$ 0.05 ) affected by extension service works (Table 2 ).

3.1.4. Influences of Landscape Factors. Results from regression analysis indicated that coffee yield ( $\mathrm{kg} / \mathrm{ha})$ was significantly $(P<0.05)$ predicted by both cultivation intensity and the distance to forest/wetland (Table 3 ). These results indicated that more yield may be obtained in less intensively cultivated areas. Variations in economic value of pollination services (value of bees in US\$/ha/year) were significantly predicted by cultivation intensity and forest distance predictors (Table 3 ). Net revenue (profitability) was not predicted by either proportion of seminatural habitats or cultivation intensity although (Table 3).

In addition, single linear regression analysis results indicated that cultivation intensity was negatively related to both coffee yield (Figure 5(a)) and gross revenue (Figure 5(b)) and to the economic value of bees (Figure 5(c)). This result indicated that agricultural intensification affected negatively the value of different economic measures of coffee production. The proportion cultivation intensity explained $22.5 \%, 27.88 \%$, and $53.38 \%$ of the variation in coffee yield, gross revenue, and value of bees to coffee production, respectively (Figure 5). In terms impacts on economic measures of coffee production, coffee yield diminished roughly by 2 -fold (Figure $5(\mathrm{~b})$ ) and gross revenue reduced by 3 -fold (Figure 5(b)) whereas value 


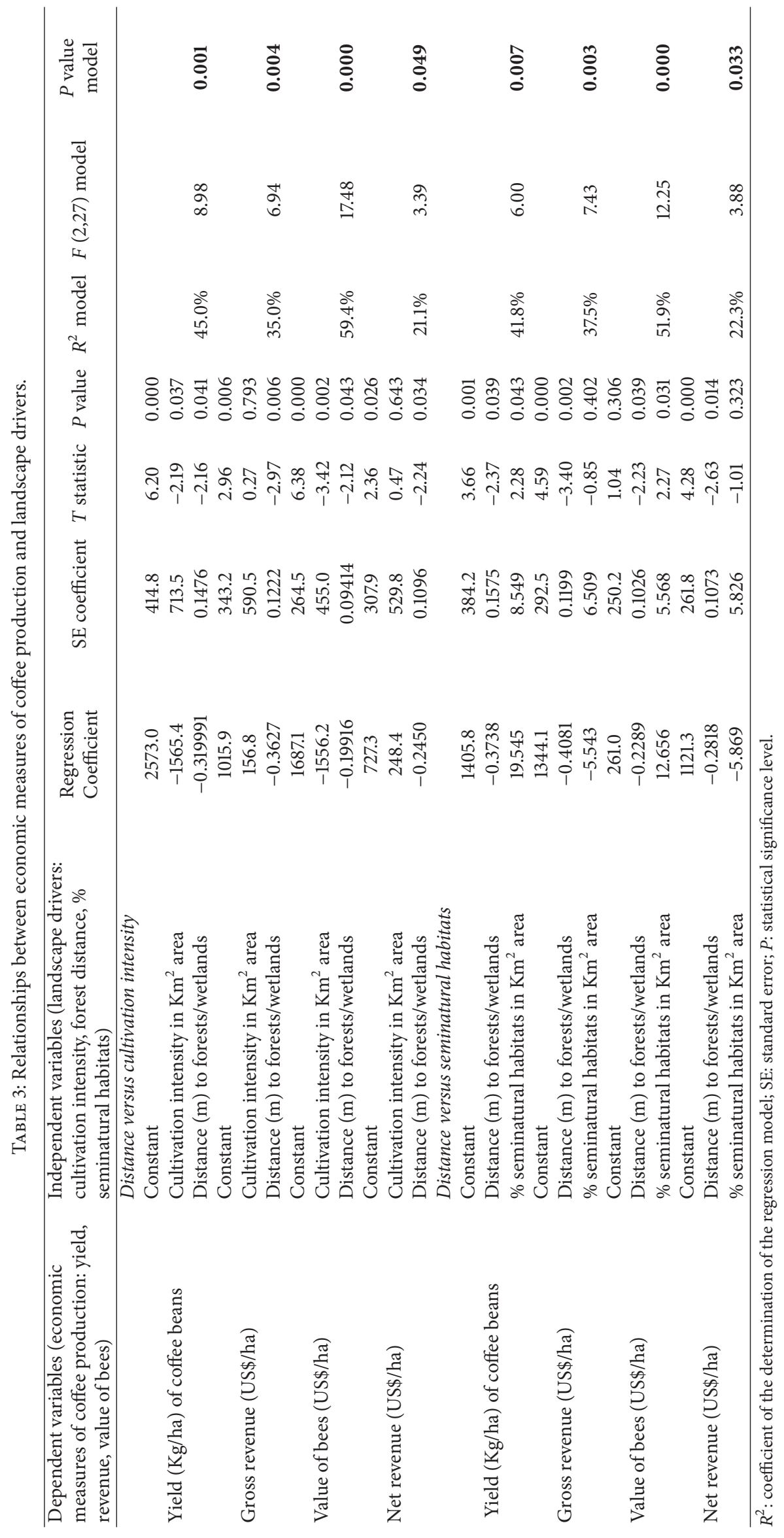




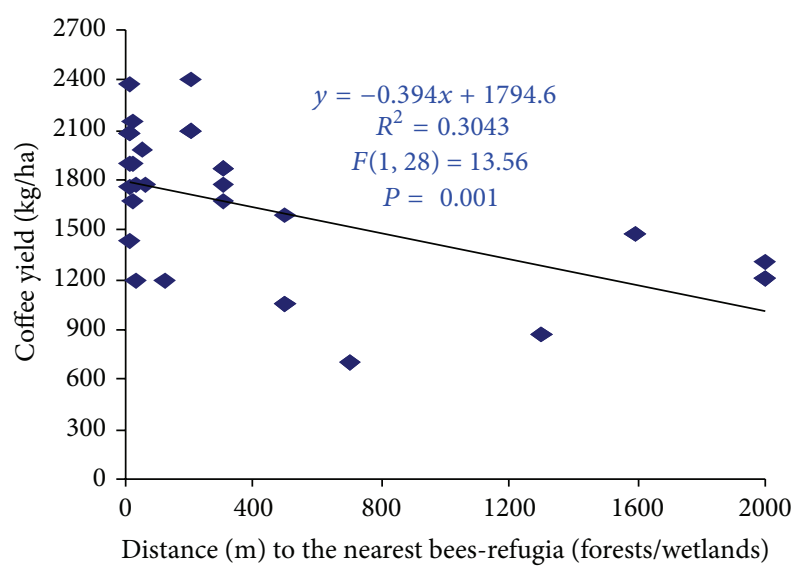

(a)

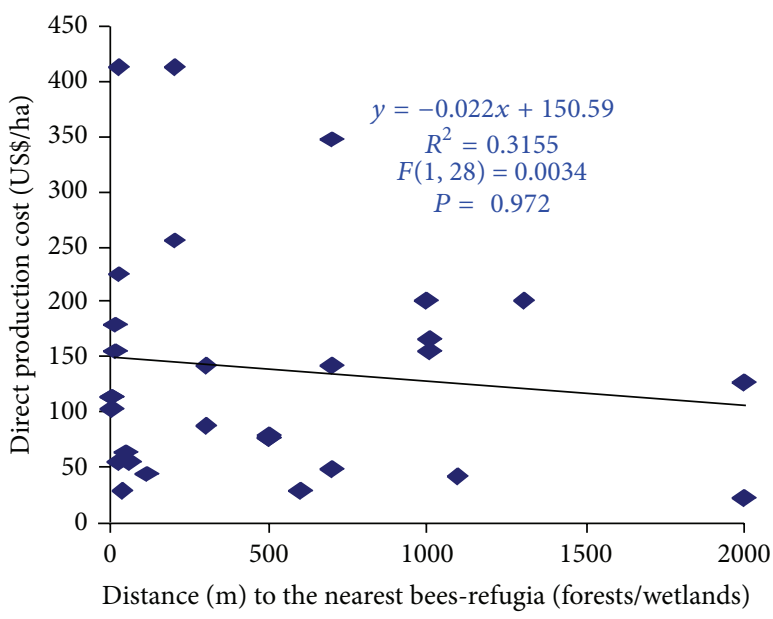

(c)

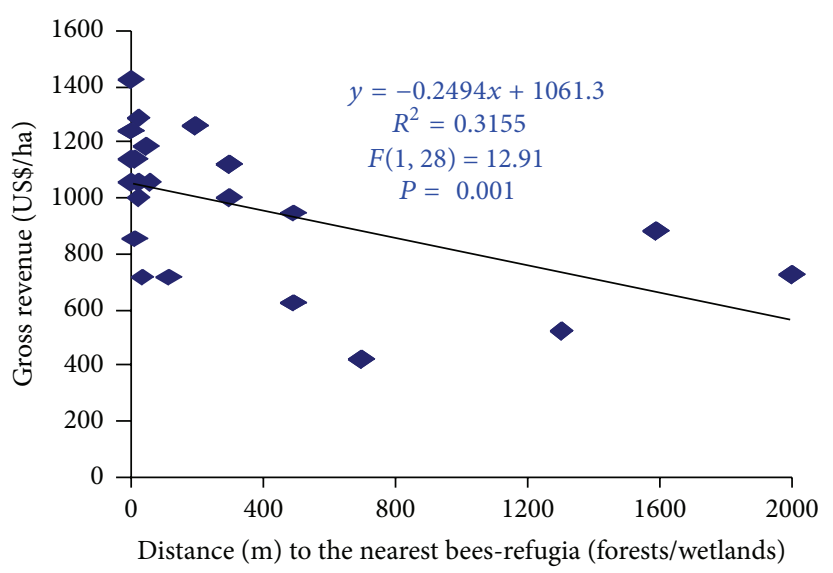

(b)

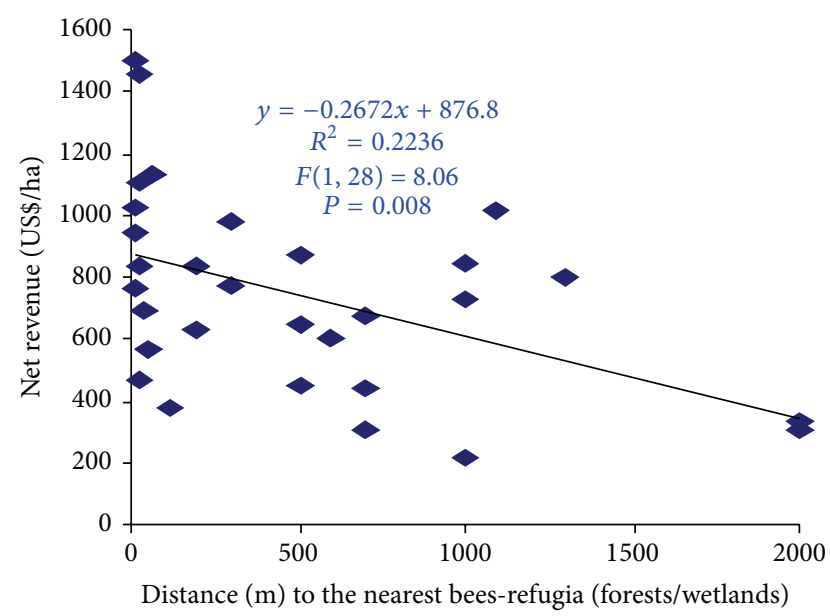

(d)

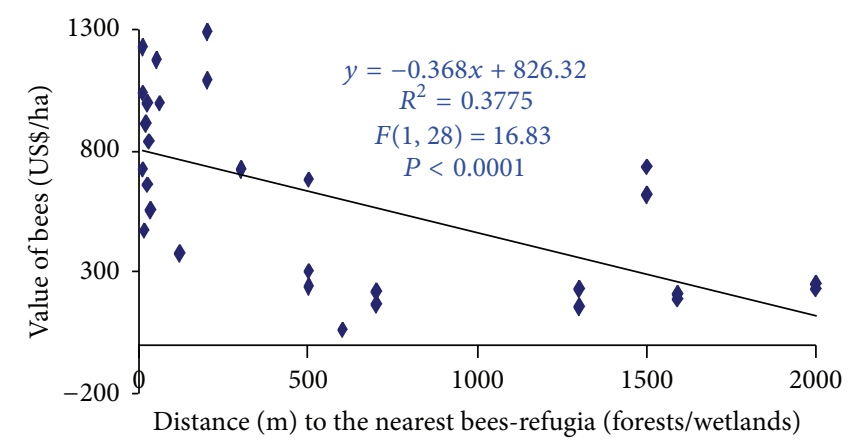

(e)

FIGURE 6: Relationship between distance to the nearest bee-refugia (forests, wetlands, and forest fallows) and the coffee production and pollination economics valuation measures: (a) yield ( $\mathrm{kg} / \mathrm{ha})$; (b) gross revenue (US\$/ha); (c) direct cost of production (US\$/ha); (d) net revenue (profitability) (US\$/ha); (e) the value of bees to coffee (US\$/ha).

of bees declined roughly by 7-fold (Figure 5(c)) with cultivation intensity.

The distance to forest/wetlands was significantly negatively related to coffee yield (Figure 5(a)), gross revenue (Figure 6(b)), net revenue (Figure 6(d)), and the value of bees (Figure 6(e)). However, forest distance was not significantly $(P>0.05)$ related to the direct cost of coffee production (Figure 6(c)). Thus, values of economic measures of coffee production (yield, gross revenue, and values of bees) and the net revenue (profitability) strongly declined with increasing distance from the forest, whereas the cost of production was not linked at all to forest distance. Overall, forest distance accounted for $30 \%, 31 \%, 22 \%$, and $37 \%$ of the variation in coffee yield, gross revenue, net profitability (net revenue), and the value of bees, respectively (Figure 6). In terms of impacts of the drivers, economic values of pollination services were 


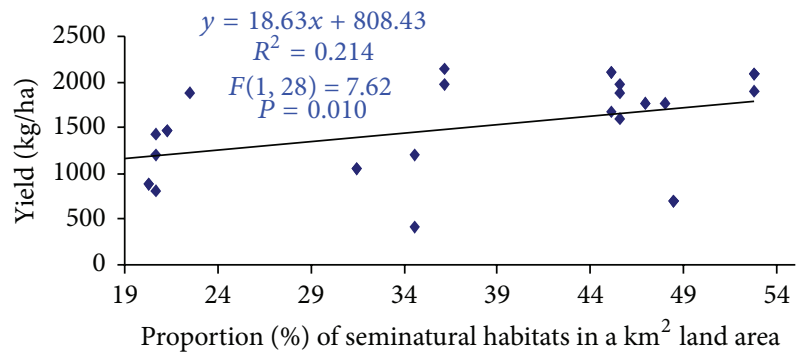

(a)

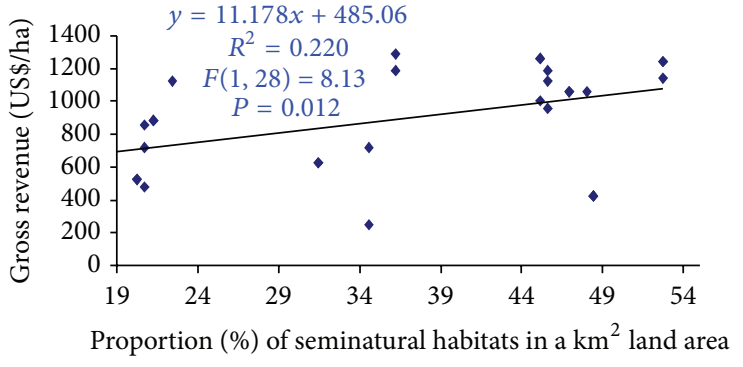

(b)

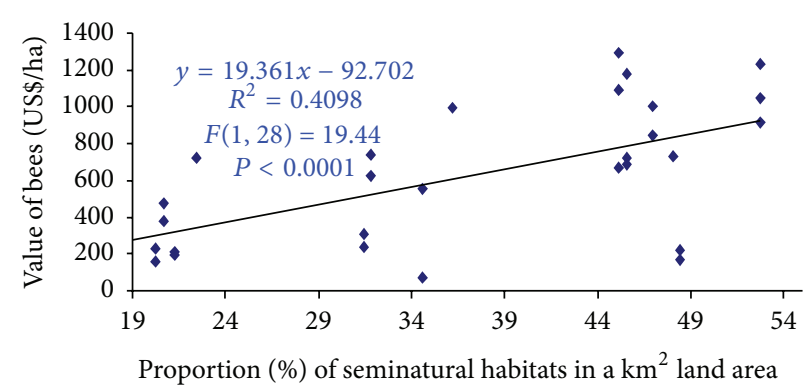

(c)

Figure 7: Relationships between the proportion (\%) cover of seminatural habitats (fallows, hedgerows, field margins, grasslands, swampy habitats, abandoned gardens) and the economics of coffee production measures: (a) yield (kg/ha); (b) gross revenue (US\$/ha); (c) the value of bees to coffee production (US $\$ /$ ha). $R^{2}=$ coefficient of the determination of the regression model; SE $=$ standard error; $P=$ statistical significance level $i$ ? bhlt? $\dot{i}(1,28)=$ values if degrees of freedom; $F=$ analysis of variance value of Snedecor test.

found declining significantly $(P<0.05)$ by $84.61 \%$ (Figures 6(a), 6(b), and 6(e)) with forest distance. Similarly, net revenue of pollination services diminished by $75 \%$ (Figure 4) with forest distance.

The proportion cover of seminatural habitats was also found to be positively related to coffee yield (Figure $7(\mathrm{a})$ ), gross revenue (Figure $7(\mathrm{~b})$ ), and the value of bees (Figure $7(\mathrm{c}))$. The result indicated a significant $(P<0.05)$ increase in yield, gross revenue, and economic value of bees with increase in the proportion of seminatural habitats in the farm landscape of $1 \mathrm{~km}^{2}$. These relationships suggested also that the stability of pollination services provided by native bee community increased as proportional area of uncultivated wild land habitat increased around a coffee farm. It is likely that increment of by $62 \%$ in the proportion cover of seminatural habitats may result in an increase per hectare of (i) $54.5 \%$ of coffee yield, (ii) $66.7 \%$ of gross revenue, and (iii) $83.3 \%$ of the economic value of bees (Figure 7).

3.1.5. Effects of Regional Land-Use Intensity. There were significant effects of the land-use intensity gradients on coffee yield (Figure 8(a)), gross revenue (Figure 8(b)), and the mean economic value of bees (Figure $8(\mathrm{c})$ ). The highest coffee yield was observed in low intensity land-use followed by mediumintensity land-use, and the lowest was observed in highland-use intensity gradient (Figure 8(a)). Pollination services received by coffee fields established in low-intensity landuse areas increased coffee yield by (i) $48.44 \%$ as compared to coffee fields established in high-land-use intensity. These also increase revenue by (ii) $24.7 \%$ as compared to coffee fields established in medium intensity land-use category (Figure 8(a)). Thus, small-scale farmers having their coffee fields established in low land-use intensity areas earned $48.4 \%$ more money from sale of coffee beans per annum as compared to farmers who had established their coffee plantations in areas with high-land-use intensity (Figure 8(b)).

In terms of impacts of regional land-use intensity, economic value of bees were observed to be significantly (LSD test, $P<0.05$ ) higher in coffee fields located in low land-use intensity category compared to coffee fields located in areas of medium or high-land-use intensity gradients (Figure 8(c)). Thus, the value of bees from coffee fields located in medium intensity land-use gradients was $53 \%$ greater than that obtained from coffee plantations established in highland-use intensity gradients (Figure 8(c)).

3.2. Effects of the Farm Size. The size of farms owned by small scale farmers ranged from 0.25 ha to 10 ha. Across coffee fields, there was high oscillation in coffee yield, revenues, and costs (Table 4). The price paid at the farmer gate level varied from 0.2 to $0.88 \mathrm{US} \$ / \mathrm{kg}$. There was a positive relationship between the size (ha) of the coffee field and its production in terms of kilograms of coffee beans harvested per annum $\left(R^{2}\right.$ $\left.=84 \%, F_{1,28}=153.37, P<0.001\right)$. The relationship indicated that the amount of coffee produced per annum by a smallscale farmer increased with the increase in the size of coffee fields. Similar pattern was observed for the gross revenue $\left(R^{2}\right.$ $\left.=89.8 \%, F_{1,28}=246.7, P<0.001\right)$ and the net revenue $\left(R^{2}\right.$ $\left.=79.8 \%, F_{1,28}=123.4, P<0.001\right)$. The positive impact of 


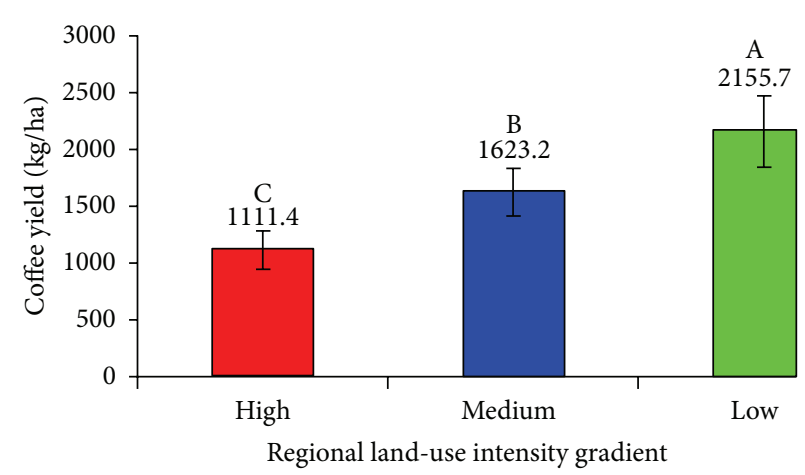

(a) [GLM-ANOVA: $F=5.13, P=0.03, \mathrm{DF}=(2,27)]$

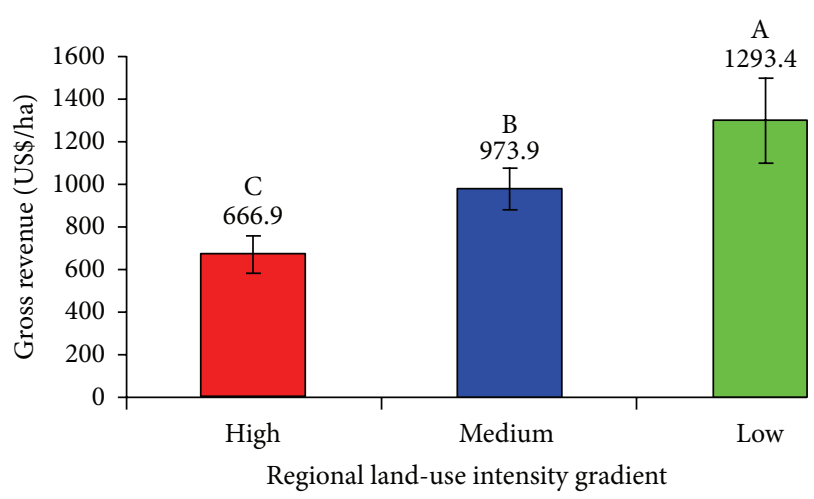

(b) [GLM-ANOVA: $F=4.06, P=0.042, \mathrm{DF}=(2,27)]$

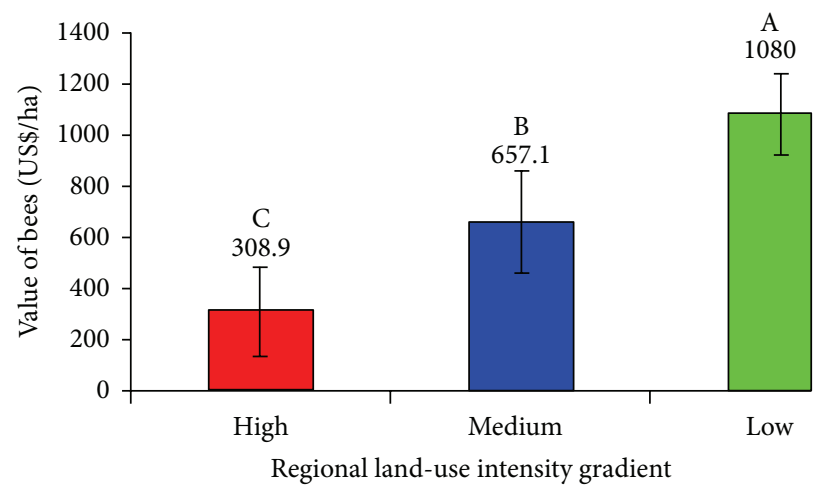

(c) [GLM-ANOVA: $F=5.79, P=0.0017, \mathrm{DF}=(2,27)]$

FIGURE 8: Effect of regional land-use intensity gradients on economics of coffee production measures ((a): coffee yield; (b): gross revenue, (c): value of bees = value of pollination services). Different letters above the bars indicate significant differences of means $(X \pm S E)$ between landuse categories at $P \leq 0.05 . R^{2}=$ coefficient of the determination of the regression model; $\mathrm{SE}=$ standard error; $P=$ statistical significance level, $(1,28)=$ value for degrees of freedom $(D F) ; F=$ analysis of variance value of Snedecor test; GLM-ANOVA = general linear model analysis of variance.

the size of the farm on revenues suggested that the majority of small-scale famers incurred lower production costs. There was also a positive relationship between the value of pollination services and the size of the farm $\left(R^{2}=89.8 \%, F_{1,28}=\right.$ 135.91, $P<0.001)$ suggesting that farmers who had coffee fields of big size benefited more (compared to farmers with small size of the field) from pollinator activities. For these lucky farmers, the value of pollination services seemed to increase with the increase in the size of the coffee field. The overall average yield of coffee was found to be significantly ( $T=3.45, P<0.05, n=30)$ higher $(2095.7 \mathrm{~kg} / \mathrm{ha})$ in the second (March-May) harvesting season (51\% of total annual production) than that in the first (September-November) harvesting season $(994.6 \mathrm{~kg} / \mathrm{ha})$.

3.3. Economic Value of Pollination Services. There was a seasonal variation in the value of pollination services delivered by bees across coffee fields (Table 4 ). Also the pollinator dependency factor varied across study sites (Table 4). It was influenced positively/negatively by the variation in richness and abundance of pollinators in the different coffee fields studied. The variability in dependency factor was a consequence of coffee flowers being visited by a bee community rich in species and functional groups with different pollinator efficiency levels [23]. The variability in the dependency factor was also influenced by the landscape context factors (forest distance and percent cover of seminatural habitats).

The pollinator dependency factor is an indicator of the pollination contribution to production value per hectare. Across coffee fields studied, the estimated economic value of pollination services delivered to coffee, that is attributable to bees, ranged from US $\$ 124 /$ ha/year to US $\$ 992 /$ ha/year, with an overall mean of US\$ $650 \pm 101 / \mathrm{ha} /$ year. The average value (US\$ 650/ha/year) of pollination services was a measure of the impact of pollination service on human welfare at the small-scale farm level. Thus, welfare to a farmer (total value generated by the pollination services in a coffee farm) varied between US\$ $63 \pm 13$ and US\$2420 \pm 385 (Mean \pm SD). The variability in the welfare is a consequence of variability in price, pollinator dependency ratio, and coffee farm sizes across study fields. Great loss in pollination services across fields may lead to high variation in increase of coffee production as a consequence of decline in pollination services provided by bees. Such vulnerability of coffee production due to decline in bees can force farmers to adapt and to switch to alternative production methods in order to reduce fixed costs or to alternative crops. 


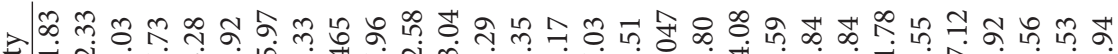

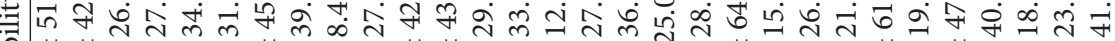
年 $+1+1+1+1+1+1+1+1+1+1+1+1+1+1+1+1+1+1+1+1+1+1+1+1+1+1+1+1+1$

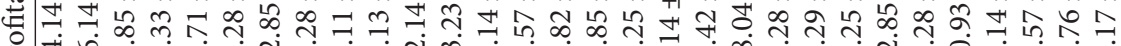

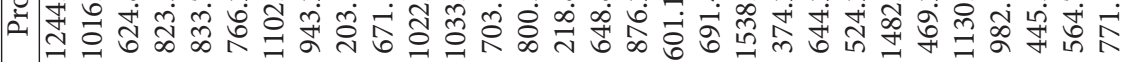

फ $\infty$

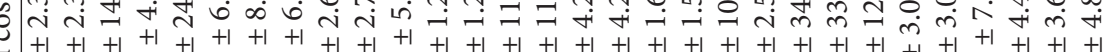
正舟

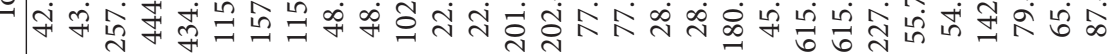

๖ํำ

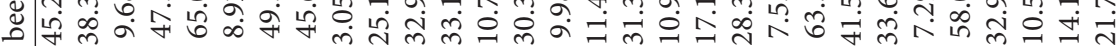
$4+1+1+1+1+1+1+1++1+1+1+1+1+1+1+1+1+1+1+1+1+1+1+1+1+1+1+1+1+1$ Ð

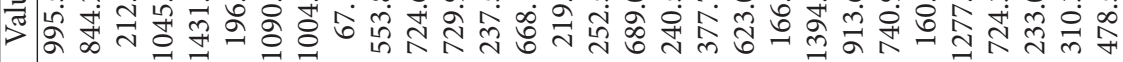

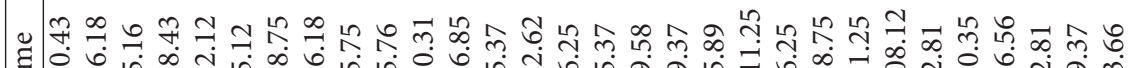
官

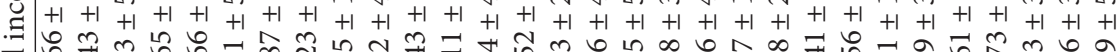
궁

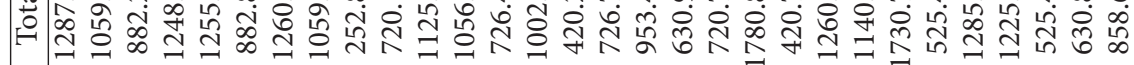

ț $+1+1+1+1+1+1+1+1+1+1+1+1+1+1+1+1+1+1+1+1+1+1+1+1+1+1+1+1+1+1$

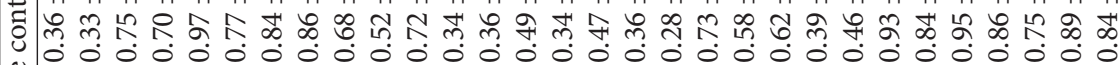

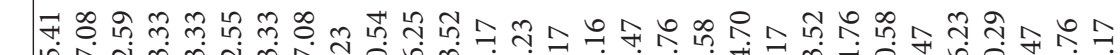

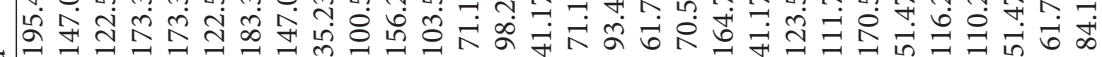

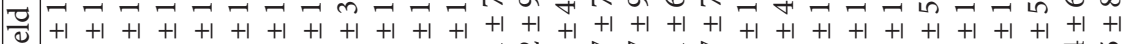

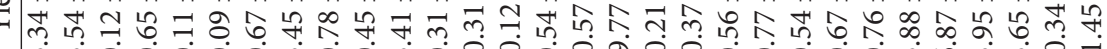

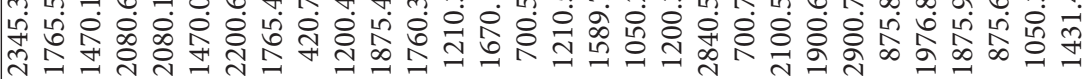

\section{$\vec{\circ} \bar{\circ}$}




\section{Discussion}

\subsection{Impacts of Social and Ecological Drivers}

4.1.1. Effects of Bee Diversity. Results from this study indicate that both bee diversity and density were significantly $(P<$ 0.05 ) related to coffee yields, gross and net revenues. The study, for the first time in sub-Saharan Africa, demonstrated that coffee yield was positively related to bee density and diversity. This indicated that bees were among the determinants production factors of coffee in the region. By assessing the effect of species richness and density on coffee yield, it was observed that both bee diversity and density accounted for significant variation in the coffee production. In fact, species richness changed in linear fashion rather than in humpshaped fashion as expected [33, 34]. Coffee yield (kg/ha) of unprocessed but dried coffee beans was found to be positively related to both the number of species of flower visiting bees per coffee field and with bee density per coffee tree. This relationship suggested that an increase in coffee yield was a direct consequence of increase in the diversity and density of coffee flower-visitors. This finding also indicated that the abundance and diversity of bees visiting coffee are important for maintaining fruit set and increasing yield in coffee.

Although there exist discrepancies and lack of linearity between biodiversity-productivity relationships in nature versus those in experiments, there exist; however, some lines of evidence indicating that the conservation and maintenance of high species diversity at micro, local, and regional scaled levels can enhance ecosystem functioning and the provision of multiple ecosystem services, as well as enhancing productivity in real world [35]. While Wossink and Swinton [36] found that the contribution of pollination services (measured as total flower-visitation frequency) to crop productivity $(\mathrm{kg} / \mathrm{ha})$ rises with increased nearby pollinator habitat (\% of seminatural habitats) following a nonlinear relationship; the relationship of coffee yield and bee community (abundance and diversity) seems to be linear (not curvilinear) in Uganda agricultural environment, meaning that availability of diversified bee communities enhances coffee yield. It is likely that the shape of the relationship may be a curve or linear depending on the type of crop produced.

Based on extrapolation from empirical experiments involving single or multiple farms, very substantial monetary values attributable to pollination services rendered by bees to coffee have recently been suggested, especially from tropical Asia and Neotropical regions [37, 38]. Results obtained in Uganda about the increase of coffee yield and revenues with bee diversity and density supported findings from previous experiments [37-39] conducted in small-scale farms in Neotropical regions. The correlation between yield (kg/ha) and bee density/diversity as found in central Uganda corroborates previous works that showed the contribution of bee pollination to fruit development by analyzing experimental treatments [37, 39, 40].

The data from central Uganda revealed that an increase in $40-100 \%$ of the density/diversity of bees would be associated with approximately $90 \%$ increase in the coffee yield, particularly for coffee fields located nearby forest reserves.
These relationships indicated also that a fourfold increase in the density/diversity of bees was even associated with a $300-450 \%$ increase in the gross/net revenues. Consequently, in central Uganda, higher yield associated with increased pollination services delivery generated higher revenues per hectare; for example, farm profit was higher when bees were abundant and diverse. Economic observations similar to those obtained in central Uganda were recently published from coffee plantations in Ecuador. In this country, it was demonstrated that a fourfold increase in bee density was associated with an $80 \%$ increase in yield and an $800 \%$ increase in net revenues $[39,40]$. These results indicated that bees could provide services of high economic value to coffee and to multiple other crops $[14,26,40,41]$ in tropical regions. These findings emphasised the need for supporting conservation efforts for bees and ecosystem service they provide across tropical rural landscapes.

4.1.2. Effects of Farm Management Intensity and Coffee Genotypes. Results of this study indicated that agronomic factors (coffee varieties) had significant $(P<0.05)$ influences on direct cost of production. Coffee varieties had no significant $(P>0.05)$ effects on coffee yield, gross revenue, net revenue (profitability), and the value of bees. On the contrast, the local farm management system was found to be one of the primary drivers with powerful influences on coffee production economic measures (yield, gross revenue, net revenue, and value of bees) and on agronomic/economic performance (productivity) of small-scale coffee farms found in central Uganda. In fact, farm management intensity had strong $(P<$ 0.05 ) influences on coffee yield, gross revenue, profitability, and value of bees in Uganda. Similarly in Mexican coffee plantations, it was observed that farm management intensity influenced significantly $(P<0.05)$ the diversity of flowervisiting bee species, the visitation frequency, and the resultant coffee yield [14].

Local bee density and diversity and economic values of pollination services were the highest in organic farms followed by traditionally managed farms; they were the lowest in intensive commercial farms, revealing high profitability associated with organic management system (high use of organic products) system. High economic values of pollination services were not associated with commercial farms because of high use of industrial agrochemicals.

Farmers who had extensive-traditional farms received lower yields/revenues than coffee growers who had intensivecommercial farms and those with intensive-organic coffee farms. The economic value of pollinating services was 2 times higher in intensive-commercial farms and 1.5 times higher in intensive-organic farms in comparison to extensively managed (traditional) farms. Commercial farms were expected to perform better than organic and traditional farms; however, this was not the case, probably because commercial farming system involves pollinator-unfriendly farming practices (use of herbicides, pesticides) that may impact of activities of bees, leading to pollination deficit. Another reason for low profitability (economic return) could be that commercial farms undergo higher cost of production than organically 
managed farms or coffee trees grown in the traditional systems.

Overall, coffee yield tended to decrease with increases in management intensity (from traditional to commercial farms). In all cases, coffee production was much bigger in commercial farms and in organic farms than in traditional farms and this indicated that the production is related to cultivation system and to coffee field management system. In Mexico, recently, it was found that low-impact management systems had higher species diversity and higher coffee fruit production than high-impact management systems [14]. Vergara and Badano [14] concluded that the diversity of insect pollinators can be influenced by the management system applied by farmers and that such effects may have strong consequences on coffee fruit production and revenue [4146].

Similarly, in Indonesia, an investigation on the impacts of the variation in management interventions (fertilization, irrigation, and shade cover) and environmental variables such as rainfall (which stimulates coffee flowering across all plantations), soil $\mathrm{pH}$, and nitrogen availability on pollination services and coffee production was carried out [2]. The results indicated that bee abundance improved coffee production (number of berries harvested). In addition, some management interventions, such as irrigation, used once to trigger asynchronous flowering, dramatically increased bee abundance at coffee trees. Others, such as the extent and type of tree cover, revealed interacting effects on pollination and, ultimately, crop production. The effects of management interventions, notably irrigation and addition of lime, had, however, far more substantial positive effects on coffee production than tree cover. These results suggested that pollination services matter in crop production, but managing the asynchrony of flowering was a more effective tool for securing good pollination than maintaining high shade tree densities as pollinator habitat [2]. Overall, it was concluded that complex interactions across farm and landscape scales, including both management practices and environmental conditions, shape pollination outcomes. Because it was realized that ecosystem services are shaped by the coupling of management interventions and environmental variables, effective production systems require therefore integrated consideration of management practices in the context of the surrounding habitat structure [2].

4.1.3. Effects of Forest Distance. In this study, coffee yield and gross revenue declined linearly with forest distance and the result indicated that coffee yield and gross revenue were higher in coffee fields located near forest fragments compared to coffee field located far from forest/wetland habitats. Similarly, strong diminishing net revenues with forest distance were also recorded although the direct cost of production incurred by small-scale farmers was not driven by forest distance.

The economic value of pollination services declined linearly with forest distance, and this result indicated that coffee plantations located in the immediate surroundings of forest fragments had higher economic profits derived from pollination services than those that were not located in the vicinity of forest fragments. It has been reported that bees do increasing yield of coffee plantations established near forest fragments. Thus, coffee farms that are riparian of large primary/secondary forests are likely to have higher yields than those located far from these forests. In other words, forest ecosystems are the best habitats for various good pollinator species of coffee $[46,47]$.

Not only that forest fragments play a significant role in the delivery of pollination services but also they determine the revenue of small-scale coffee growers. Hence, destroying forests adjacent to coffee systems can reduce pollination services significantly. In highly fragmented landscapes like those found in central Uganda, small forest remnants are of high ecological/economic importance in terms of contribution to the revenue of small-scale coffee growers. The destruction/degradation of forests in the surrounding (in the first 100-200 m of forest margins) of coffee fields is estimated to bring enormous economic losses to small-scale coffee growers in Indonesia (125 US\$/ha) and in Ecuador (US\$ 71/ha) [48].

In this study, it was found that coffee yield from fields located at the margins of forest fragments was $90 \%$ higher than the yield from coffee fields located $2 \mathrm{~km}$ far way from forest margins. Proximity to natural habitat and related seminatural habitats enhances both the magnitude and stability of pollination services provided by wild bees to coffee grown under various farming systems led by small-scale farmers in central Uganda. In Costa Rica, Ricketts et al. [6] found a $20.8 \%$ increase in coffee yields near two patches of native forests. This percentage increase generated approximately US\$ 62,000/year/coffee farm and this amount came directly from the adequate pollination services provided by adjacent forests. In contrast, coffee fields that were found not located in vicinity (those located far away) of forested lands had an increase in yield of less than $11.5 \%$ [6]. Also, the value of pollination services provided by forest to coffee in the annual net revenues has been said to increase when plantations are placed nearest to forest ecosystems. In fact, in Indonesia, an analysis based on the contribution of pollination services to gross revenue concluded that the average pollination value was US\$ 33/ha in coffee fields located in deforested area; however, this value was about $23 \%$ (US\$ $57 /$ ha/year) higher in coffee fields located near forest patches. Overall, in Ecuador, the value of pollination to coffee was on average 57-76 US\$/ha in coffee fields located in deforested areas, and in areas covered with forests, this value was about $57 \%$ more higher [48]. These results indicated diverse economic values of bees to coffee across tropical regions characterized by different ecological and production systems.

While, in Costa Rica, Ricketts et al. [6] Found that significant effect of insect pollination on yield of coffee tree crop was high at distances up to 700-800 $\mathrm{m}$ from forest fragments and that at 1400-1600 m distance far from the forest, the effect was lost.

De Marco and Coelho [12] found an increased pollination effect on crop production at distance of $1000 \mathrm{~m}$ far from forest fragments. Results obtained in central Uganda concur with these findings of De Marco Jr. and Coelho [12] since it was 
observed that at a distance of $2000 \mathrm{~m}$, coffee yield declined by about $85-90 \%$ compared to coffee farms established in the very proximity of forest patches/wetlands.

The value of pollination as an ecosystem service for coffee fields established close to native forests was found to be US\$ $1880.55 /$ ha/year in Brazil [12]. A lower value (US\$ 900/ha/year) was observed in central Uganda. In Costa Rica, the enhanced value of coffee production attributed to pollination by wild bees was estimated to be US\$393/ha/year when coffee fields were established close to forest margins $[6,46]$. In contrast, in Indonesia, for an average yield ranging from $468 \mathrm{~kg} / \mathrm{ha}$ to $891 \mathrm{~kg} / \mathrm{ha}$, the enhanced average value of coffee production attributed to wild bee pollination service was estimated at only US\$ 55-62/ha/year when coffee fields were established in the margins of forest remnants [47-49]. Results similar to those obtained in Indonesia were also reported in Ecuador [46]. The variability in values reported by different authors may be due to differences in ecological conditions of the different study sites.

4.1.4. Effects of Seminatural Habitats. In this study, it was found that an increase in yield, gross revenue, and economic value of bees was positively associated with an increase in the percent cover seminatural habitats in the farm landscape of $1 \mathrm{~km}^{2}$. In terms of landscape management, an increment of approximately $62.9 \%$ in the proportion cover of seminatural habitats is likely to result in an increase per hectare of $54.5 \%$ in yield, $66 \%$ in gross revenue, and $83.3 \%$ in the economic value of bees. These results further indicated that keeping seminatural habitats around coffee production plantations is highly invaluable in sustaining coffee production in central Uganda. Positive relationships, between crop yield per unit area, diversity/abundance of pollinators, and the amount of native vegetation in the area around the crop, are reported [50-54]. Recently, the Brazilian environmental law agency requested to rural landowners to keep $20 \%$ of the native vegetation on their farms [12] as reservoir for bees pollinating their coffee trees. In Uganda, farmers are requested to keep at least $20-40 \%$ of their land uncultivated to get higher benefit from pollination services $[17,23]$. Thus, natural environments are important sources of pollinators offering enormous pollination benefits, probably because they provide good nesting sites and food resources, particularly if they are spatially integrated into the agricultural matrix [54]. Maintaining pollinator habitats in agricultural landscapes, therefore, can help ensure food production, quality, and security.

4.1.5. Effects of Regional Land-Use Intensity. Results from this study indicated that regional land-use had significant influences on economic measures of coffee production in central Uganda. Gross revenue was found to be significantly greater in low land-use intensity compared to high-land-use intensity. The fact that the lowest gross revenue was associated with high-land-use intensity indicated that small-scale coffee farmers should not choose to grow coffee in farm-landscapes that are intensively cultivated because their coffee farms may become $36 \%$ less profitable than those established in areas with low land-use intensity.
4.1.6. Effects of Agricultural Extension Services Providers. The results of this study indicated that agronomic factors (coffee varieties) and social-economic-development factors (agriculture extension services) had significant $(P<0.05)$ influences on direct cost of production. However, both types of drivers had no significant $(P>0.05)$ effects on coffee yield, gross revenue, net revenue (profitability), and the value of bees.

The reliable media used by scientists and development activists are through the extension institutions. Messages are delivered in rural areas by different extension agencies to improve livelihood of small-scale coffee farmers through enhancing their crop productivity. The fact that extension service dissemination messages (agricultural interventions) by different extension agencies did not influence coffee yield and revenues in central Uganda was difficult to explain. However this indicated existence of some technical problems in the functioning of the national extension system piloted by PMA (Plan for the Modernization of Agriculture in Uganda) and implemented by NAADS (National Agriculture Advisory Services) and collaborators. Either all farmers receive little information related to the improvement of coffee productivity from these extension service agencies or extension agents do not convince farmers to adopt the proposed agricultural technologies. Such situation of lack of significant impacts of the national extension service could also be attributed to the fact that extension services mandated to deliver extension advices to farmers have not yet done good job to bring a significant ecological-economic impact on coffee farms.

The fact that agriculture interventions and coffee genotypes influenced significantly $(P<0.05)$ the direct cost of production was less understood. At the moment, no sound explanation can be offered. However, it looks like that farmer growing improved coffee varieties had higher costs of production because the management of improved varieties implies too much care. It is well known that the adoption of improved varieties requires the producer to invest more efforts and inputs to be able to obtain good results. Improved varieties (clonal coffee) may be more susceptible to environmental or management stresses than bush varieties, thus requiring more input from the farmer to adapt the production system.

4.1.7. Effects of Farm Size. Results of this study indicated that economic measures of coffee production were positively related to farm size; for example, any increase in the farm size led to the certain increment in the value of different economic measures of coffee production. The fact that higher yield and revenues were associated with farm size increase is not so evident in agricultural systems because the productivity of a coffee farm depends not only on the production of each individual coffee tree (2-9 kg of dry coffee beans), but also on the number of coffee trees planted and on other production factors. Hence, the more farm size is increased, the more the production of the farm is high. Consequently, coffee farms with higher yields are likely to have greater revenues. In agricultural economics, the effects of farm size on yield and revenues are still topics of debate [55-57]. In most agricultural systems in the tropics, it is not common to see that people holding larger lands are those obtaining higher production 
levels. In some cases, a farmer may have a big land and still produce less compared to someone with a land of small size.

The found positive impact of the size of the farm on yield and revenues suggested that the majority of small-scale coffee famers incurred lower production costs under local conditions. This situation was favored by the fact that most coffee farms are established on more fertile lands of the country. In fact, coffee production is rarely constrained by moisture content and fertility level (nutrient elements) but may be frequently constrained by other production factors such as availability of pollinators, pests, and disease [8].

In this study, it was found that the economic value of bees for a coffee farm of large size was found to be higher when the coffee farm was surrounded by higher amount of linear and nonlinear seminatural habitats. Although a positive linear relationship was found between the size of the farm and coffee yield it may not be advised to producers to keep increasing the size without taking into account the effects of other local management factors. Increasing the size of a coffee farm will only be economically viable or profitable if plantations are established in the vicinity of forest fragments and related seminatural habitat patches or if farmers can establish pollinator reservoirs (e.g., young fallows) in the immediate fringe of coffee fields.

\subsection{Economic Value of Pollination Services Delivered to Coffee.} The results of this study indicated that on average $62 \%$ of the economic value of coffee production was attributable to pollination services delivered by bees. The overall average value of pollinating services was US\$ 650/ha/year. The increase in coffee yield associated with pollinating agents has been demonstrated in other countries out of sub-Saharan Africa [14, 46, 47]. Across tropical Asian and neotropical countries, reported economic value of pollination services are in the range of US\$ 55/ha/year to US\$ 1900/ha/year. Although local prices of coffee may be influenced by international trade/market system of coffee, the variability in reported economic values (from various countries) is largely attributable to differences in bee diversity and abundance, landscape context $[6,14,17,38,47,52,58-61]$, and farm management systems and socioeconomic drivers. Across different studies conducted on economic values of pollinating services (in Neotropical region and in tropical Asia), the differences may also be due to the diversity of farming systems studied. In other words, the type of coffee farm management adopted by the farmer contributes largely to variations in economic values. For example, in Costa Rica, Indonesia, and Ecuador and Uganda, data used to calculated economic values of pollinating services were from small-scale coffee farms whereas in Mexico, data were collected mainly from large estates of coffee plantations.

\section{Conclusion}

The aim of this study was to determine the economic significance of pollination services in coffee production in Uganda in to various agronomic and socioeconomic drivers. Findings indicated that landscape drivers, bee community variables, regional land-use intensity, farm size, and farm management intensity gradients were the primary drivers of coffee yield, revenues, and value of bees. As was reported from Mexico [14], landscape drivers together with the farm management environment systems displayed the strongest effects on coffee yield and revenues. Coffee farm management system distinctly impacted on community composition, visitation frequencies, and foraging patterns of different bee species. Coffee farm management impacts on services delivery to fruit set and on the resultant coffee yield, revenue, and profitability. The effect of coffee genotypes was not significant $(P>0.05)$. Although they have been operating for quite long to increase coffee productivity in rural central Uganda, the actions of agricultural extension service providers were found to have no effects on coffee yield and revenues.

The economic value of pollination services delivered to coffee approximated US\$ 650/ha/year on average. At the national level, the total economic value of coffee produced in Uganda is averagely US\$ 214 million from half million hectares dedicated to coffee production from which US\$ 149 million (62\%) is attributable to pollination services delivered by bees to coffee. This pollinating service value is equivalent to $24 \%$ of annual earnings from export of agricultural products by government of Uganda and to 2.99\% of her GDP (Gross Domestic Products). Overall, pollination service delivered by bees was found to be an essential ecosystem service in coffee production in Uganda. Coffee yield failure due to lack of sufficient pollination services or due to pollinator scarcity may feed back via market forces to shift growers to other commodities that require fewer or no pollinators or to change land-use/management policies.

This is the first study conducted in sub-Saharan Africa to explore the role of pollinators in coffee production and revenue in relationship with a wide range of socioecological and economic factors contributing to coffee production.

It was found in this study that pollination services are of high significance in coffee production economy. Forests, seminatural habitats, and bee diversity/density increased significantly the profitability of small-scale coffee farms. There is thus a need to advocate for pollinator biodiversity conservation in central Uganda and in other sub-Saharan Africa countries.

This papers gives an entry point for bringing ecosystem services to the attention of policy-makers who are generally unaware of the importance of valuing and protecting the natural capital. The data may be used to guide policymakers on planning and resource allocation to beekeeping and to wild pollinator's management in rural areas. Therefore, conservation organizations that guide land management and restoration should optimize conservation investments in pollinator biodiversity conservation for coffee productivity. Finally, governments (policy-makers) should create incentives (e.g., creating/proposing rewarding/payment schemes for pollination services delivery) to conserve pollinator biodiversity nearby coffee fields.

Managing coffee farms as intensive-organic farms may be a more profitable business than managing coffee farms as commercial farms that involve application of pesticides that in turn negate life of pollinators. It is recommended 
to small-scale coffee farmers from central Uganda to adopt and preserve at least $20-40 \%$ of their land uncultivated (uncropped areas) as pollinator reservoir $[17,61]$ to make coffee productivity remains ecologically and economically viable on a long-term basis. Ecological intensification rather than chemical intensification in coffee/crop production should be prioritized.

Future research on this topic should seek to isolate and determine the exact contribution of pollinators to the yield of coffee as compared to other coffee productions factors (soil nutrients, water). There is also a need to map and develop models that may help to predict the future and vulnerability/sensitivity of pollination services delivery to coffee and to other crops under current climate change threats.

\section{Ethical Approval}

Ethical issues (including plagiarism, informed consent, misconduct, data fabrication and/or falsification, double publication, and redundancy, etc.) have been completely observed by the author.

\section{Conflict of Interests}

The author declares that there is no conflict of interests regarding the publication of this paper.

\section{Acknowledgments}

The author is very grateful to Darwin Initiative (Defra, UK; Project Reference: 14-032) for funding this study under the project title: Conserving Biodiversity in Modernized Farm Landscapes in Uganda. He is also very grateful to farmers for offering their farms for pollination experiments and for their kind cooperation during data collection. He thanks Mr. Maurice Mutabazi (research assistant) for his assistance in the field. He is also very grateful to project leaders for all kind of help given to him during the course of this study.

\section{References}

[1] A. G. Power, "Ecosystem services and agriculture: tradeoffs and synergies," Philosophical Transactions of the Royal Society B, vol. 365, no. 1554, pp. 2959-2971, 2010.

[2] V. Boreux, C. G. Kushalappa, P. Vaast, and J. Ghazoul, "Interactive effects among ecosystem services and management practices on crop production: pollination in coffee agroforestry systems," Proceedings of National Academy of Science, vol. 110, pp. 8387-8392, 2013.

[3] S. M. Philpott, T. Dietsch, J. H. Rappole, D. I. King, and J. H. Vega Rivera, "Coffee and conservation: a global context and the value of farmer involvement," Conservation Biology, vol. 17, no. 6, pp. 1844-1849, 2003.

[4] I. Perfecto, J. Vandermeer, A. Mas, and L. S. Pinto, "Biodiversity, yield, and shade coffee certification," Ecological Economics, vol. 54, no. 4, pp. 435-446, 2005.

[5] I. Perfecto and J. Vandermeer, "Biodiversity conservation in tropical agroecosystems: a new conservation paradigm," Annals of the New York Academy of Sciences, vol. 1134, pp. 173-200, 2008.

[6] T. H. Ricketts, G. C. Daily, P. R. Ehrlich, and C. D. Michener, "Economic value of tropical forest to coffee production," Proceedings of the National Academy of Sciences of the United States of America, vol. 101, no. 34, pp. 12579-12582, 2004.

[7] C. Gordon, R. Manson, J. Sundberg, and A. Cruz-Angón, "Biodiversity, profitability, and vegetation structure in a Mexican coffee agroecosystem," Agriculture, Ecosystems and Environment, vol. 118, no. 1-4, pp. 256-266, 2007.

[8] T. Munyuli, "Assessment of indicator species of butterfly assemblages in coffee-banana farming system in central Uganda," African Journal of Ecology, vol. 50, no. 1, pp. 77-89, 2012.

[9] T. M. B. Munyuli, Pollinator biodiversity and economic value of pollination services in [PhD dissertation], Makerere University, UgandaKampala, Uganda, 2010.

[10] C. Kremen, N. M. Williams, and R. W. Thorp, "Crop pollination from native bees at risk from agricultural intensification," Proceedings of the National Academy of Sciences of the United States of America, vol. 99, no. 26, pp. 16812-16816, 2002.

[11] D. Veddeler, A.-M. Klein, and T. Tscharntke, "Contrasting responses of bee communities to coffee flowering at different spatial scales," Oikos, vol. 112, no. 3, pp. 594-601, 2006.

[12] P. De Marco Jr. and F. M. Coelho, "Services performed by the ecosystem: forest remnants influence agricultural cultures' pollination and production," Biodiversity and Conservation, vol. 13, no. 7, pp. 1245-1255, 2004.

[13] R. Olschewski, T. Tscharntke, P. C. Benítez, S. Schwarze, and A. M. Klein, "Economic evaluation of ecosystem services as a basis for stabilizing rainforest margins?" in The Stability of Tropical Rainforest Margins: Linking Ecological, Economic and Social Constraints of Land Use and Conservation, T. Tscharntke, C. Leuschner, M. Zeller, E. Guhardja, and A. Bidin, Eds., Environmental Science Series, pp. 265-278, Springer, Berlin, Germany, 2007.

[14] C. H. Vergara and E. I. Badano, "Pollinator diversity increases fruit production in Mexican coffee plantations: the importance of rustic management systems," Agriculture, Ecosystems and Environment, vol. 129, no. 1-3, pp. 117-123, 2009.

[15] N. Gallai, J.-M. Salles, J. Settele, and B. E. Vaissière, "Economic valuation of the vulnerability of world agriculture confronted with pollinator decline," Ecological Economics, vol. 68, no. 3, pp. 810-821, 2009.

[16] T. M. B. Munyuli, "Micro, local, landscape and regional drivers of bee biodiversity and pollination services delivery to coffee (Coffea canephora) in Uganda," International Journal of Biodiversity Science, Ecosystem Services and Management, vol. 8, no. 3, pp. 190-203, 2012.

[17] T. M. B. Munyuli, "Diversity of life-history traits, functional groups and indicator species of bee communities from farmlands of central Uganda," Jordan Journal of Biological Sciences, vol. 51, pp. 1-14, 2012.

[18] T. M. B. Munyuli, S. G. Potts, and P. Nyeko, "Patterns of bee biodiversity and conservation values of localities with contrasting mini-ecological structures found within, nearby and between agricultural mosaic landscapes from central Uganda," Life Sciences International Journal, vol. 2, no. 4, pp. 866-914, 2008.

[19] T. M. B. Munyuli, "Pollinator biodiversity in Uganda and in SubSahara Africa: landscape and habitat management strategies for its conservation," International Journal of Biodiversity and Conservation, vol. 3, pp. 551-609, 2011. 
[20] T. Munyuli, "Factors governing flower visitation patterns and quality of pollination services delivered by social and solitary bee species to coffee in central Uganda," African Journal of Ecology, vol. 49, no. 4, pp. 501-509, 2011.

[21] A.-M. Klein, I. Steffan-Dewenter, and T. Tscharntke, "Pollination of Coffea canephora in relation to local and regional agroforestry management," Journal of Applied Ecology, vol. 40, no. 5, pp. 837-845, 2003.

[22] T. M. B. Munyuli, M. Kasina, J. Lossini, J. R. Mauremootoo, and C. Eardley, "Bee genera of East Africa (Kenya38, Uganda and Tanzania)," Lucid V. 3. 5 Key and Fact Sheets, KARI, TPRI, PPRI, Busitema University, BioNETEAFRINET, CABI \& University of Queensland, 2011 http://keys.lucidcentral.org/keys/v3/ EAFRINET.

[23] T. M. B. Munyuli, "Farmers'perceptions of pollinators'importance in coffee production in Uganda," Agricultural Sciences, vol. 2, pp. 318-333, 2011.

[24] A. Dafni and G. P. Kevan, Practical Pollination Ecology, Enviroquest, Ontario, Canada, 2005.

[25] C. M. Kennedy, E. Lonsdorf, M. C. Neel et al., "A global quantitative synthesis of local and landscape effects on wild bee pollinators in agroecosystems," Ecology Letters, vol. 16, no. 5, pp. 584-599, 2013.

[26] C. Kremen, N. M. Williams, M. A. Aizen et al., "Pollination and other ecosystem services produced by mobile organisms: a conceptual framework for the effects of land-use change," Ecology Letters, vol. 10, no. 4, pp. 299-314, 2007.

[27] A.-M. Klein, B. E. Vaissière, J. H. Cane et al., "Importance of pollinators in changing landscapes for world crops," Proceedings of the Royal Society B, vol. 274, no. 1608, pp. 303-313, 2007.

[28] S. Bolwig, D. Pomeroy, H. Tushabe, and D. Mushabe, "Crops, trees, and birds: biodiversity change under agricultural intensification in Uganda's farmed landscapes," Journal of Geography, vol. 106, no. 2, pp. 115-130, 2006.

[29] M. H. Allsopp, W. J. de Lange, and R. Veldtman, "Valuing insect pollination services with cost of replacement," PLoS ONE, vol. 3, no. 9, Article ID e3128, 2008.

[30] L. Hein, "The economic value of the pollination service, a review across scales," The Open Ecology Journal, vol. 2, pp. 74-82, 2009.

[31] R. Chaplin-Kramer, K. Tuxen-Bettman, and C. Kremen, "Value of wildland habitat for supplying pollination services to californian agriculture," Rangelands, vol. 33, no. 3, pp. 33-41, 2011.

[32] R. Winfree, B. J. Gross, and C. Kremen, "Valuing pollination services to agriculture," Ecological Economics, vol. 71, no. 1, pp. 80-88, 2011.

[33] D. R. Chalcraft, B. J. Wilsey, C. Bowles, and M. R. Willig, "The relationship between productivity and multiple aspects of biodiversity in six grassland communities," Biodiversity and Conservation, vol. 18, no. 1, pp. 91-104, 2009.

[34] R. E. Green, S. J. Cornell, J. P. W. Scharlemann, and A. Balmford, "Farming and the fate of wild nature," Science, vol. 307, no. 5709, pp. 550-555, 2005.

[35] J. E. Duffy, "Why biodiversity is important to the functioning of real-world ecosystems," Frontiers in Ecology and the Environment, vol. 7, no. 8, pp. 437-444, 2009.

[36] A. Wossink and S. M. Swinton, "Jointness in production and farmers' willingness to supply non-marketed ecosystem services," Ecological Economics, vol. 64, no. 2, pp. 297-304, 2007.

[37] D. W. Roubik, "Tropical agriculture: the value of bees to the coffee harvest," Nature, vol. 417, no. 6890, p. 708, 2002.
[38] T. H. Ricketts, “Tropical forest fragments enhance pollinator activity in nearby coffee crops," Conservation Biology, vol. 18, no. 5, pp. 1262-1271, 2004.

[39] G. C. Daily, S. Polasky, J. Goldstein et al., "Ecosystem services in decision making: time to deliver," Frontiers in Ecology and the Environment, vol. 7, no. 1, pp. 21-28, 2009.

[40] J. M. Kasina, J. Mburu, M. Kraemer, and K. Holm-Mueller, "Economic benefit of crop pollination by bees: a case of kakamega small-holder farming in Western Kenya," Journal of Economic Entomology, vol. 102, no. 2, pp. 467-473, 2009.

[41] P. Hoehn, T. Tscharntke, J. M. Tylianakis, and I. SteffanDewenter, "Functional group diversity of bee pollinators increases crop yield," Proceedings of the Royal Society B, vol. 275, no. 1648, pp. 2283-2291, 2008.

[42] C. Brittain, R. Bommarco, M. Vighi, J. Settele, and S. G. Potts, "Organic farming in isolated landscapes does not benefit flowervisiting insects and pollination," Biological Conservation, vol. 143 , no. 8, pp. 1860-1867, 2010.

[43] T. M. B. Munyuli, "Trends in response to drivers by different bee ecological traits and functional groups in agricultural landscapes in Uganda," Trends in Entomology, vol. 9, no. 2, pp. $1-23,2013$.

[44] T. M. B. Munyuli, "Influence of functional traits on foraging behaviour and pollination efficiency of wild social and solitary bees visiting coffee (Coffea canephora) flowers in Uganda," Grana.

[45] T. M. B. Munyuli, "Climatic, regional land-use intensity, landscape and local variables predicting best the occurrence and distribution of bee community diversity in various farmland habitats in Uganda," Pschyche, vol. 2013, Article ID 564528, 38 pages, 2013.

[46] T. H. Ricketts, J. Regetz, I. Steffan-Dewenter et al., "Landscape effects on crop pollination services: are there general patterns?" Ecology Letters, vol. 11, no. 10, p. 1121, 2008.

[47] D. Veddeler, R. Olschewski, T. Tscharntke, and A.-M. Klein, "The contribution of non-managed social bees to coffee production: new economic insights based on farm-scale yield data," Agroforestry Systems, vol. 73, no. 2, pp. 109-114, 2008.

[48] L. A. Morandin and M. L. Winston, "Wild bee abundance and seed production in conventional, organic, and genetically modified canola," Ecological Applications, vol. 15, no. 3, pp. 871881, 2005.

[49] J. A. Priess, M. Mimler, A.-M. Klein, S. Schwarze, T. Tscharntke, and I. Steffan-Dewenter, "Linking deforestation scenarios to pollination services and economic returns in coffee agroforestry systems," Ecological Applications, vol. 17, no. 2, pp. 407-417, 2007.

[50] C. Kremen and R. S. Ostfeld, "A call to ecologists: measuring, analyzing, and managing ecosystem services," Frontiers in Ecology and the Environment, vol. 3, no. 10, pp. 540-548, 2005.

[51] L. A. Morandin and M. L. Winston, "Pollinators provide economic incentive to preserve natural land in agroecosystems," Agriculture, Ecosystems and Environment, vol. 116, no. 3-4, pp. 289-292, 2006.

[52] C. Kremen, R. L. Bugg, N. Nicola, S. A. Smith, R. W. Thorp, and N. W. Williams, "Native bees, native plants and crop pollination in California," Fremontia, vol. 30, pp. 41-49, 2002.

[53] E. Lonsdorf, C. Kremen, T. Ricketts, R. Winfree, N. Williams, and S. Greenleaf, "Modelling pollination services across agricultural landscapes," Annals of botany, vol. 103, no. 9, pp. 1589$1600,2009$. 
[54] A. D. Arthur, J. Li, S. Henry, and S. A. Cunningham, "Influence of woody vegetation on pollinator densities in oilseed Brassica fields in an Australian temperate landscape," Basic and Applied Ecology, vol. 11, no. 5, pp. 406-414, 2010.

[55] H. E. Julier and T. H. Roulston, "Wild bee abundance and pollination service in cultivated pumpkins: farm management, nesting behavior and landscape effects," Journal of Economic Entomology, vol. 102, no. 2, pp. 563-573, 2009.

[56] A. D. Sumner and C. A. Wolfe, "Diversification, vertical integration and regional pattern of dairy farm size," Review of Agricultural Economics, vol. 24, no. 2, pp. 442-457, 2002.

[57] A. K. Mishra, H. S. El-Osta, and C. L. Sandretto, "Factors affecting farm enterprise diversification," Agricultural Finance Review, vol. 64, no. 2, pp. 151-166, 2004.

[58] A.-M. Klein, I. Steffan-Dewenter, and T. Tscharntke, "Fruit set of highland coffee increases with the diversity of pollinating bees," Proceedings of the Royal Society B, vol. 270, no. 1518, pp. 955-961, 2003.

[59] R. E. Shuler, T. H. Roulston, and G. E. Farris, "Farming practices influence wild pollinator populations on squash and pumpkin," Journal of Economic Entomology, vol. 98, no. 3, pp. 790-795, 2005.

[60] A.-M. Klein, R. Olschewski, and C. Kremen, "The ecosystem service controversy: is there sufficient evidence for a pollination paradox?" GAIA, vol. 17, no. 1, pp. 12-16, 2008.

[61] Ö. Bodin, M. Tengö, A. Norman, J. Lundberg, and T. Elmqvist, "The value of small size: loss of forest patches and ecological thresholds in southern Madagascar," Ecological Applications, vol. 16, no. 2, pp. 440-451, 2006. 

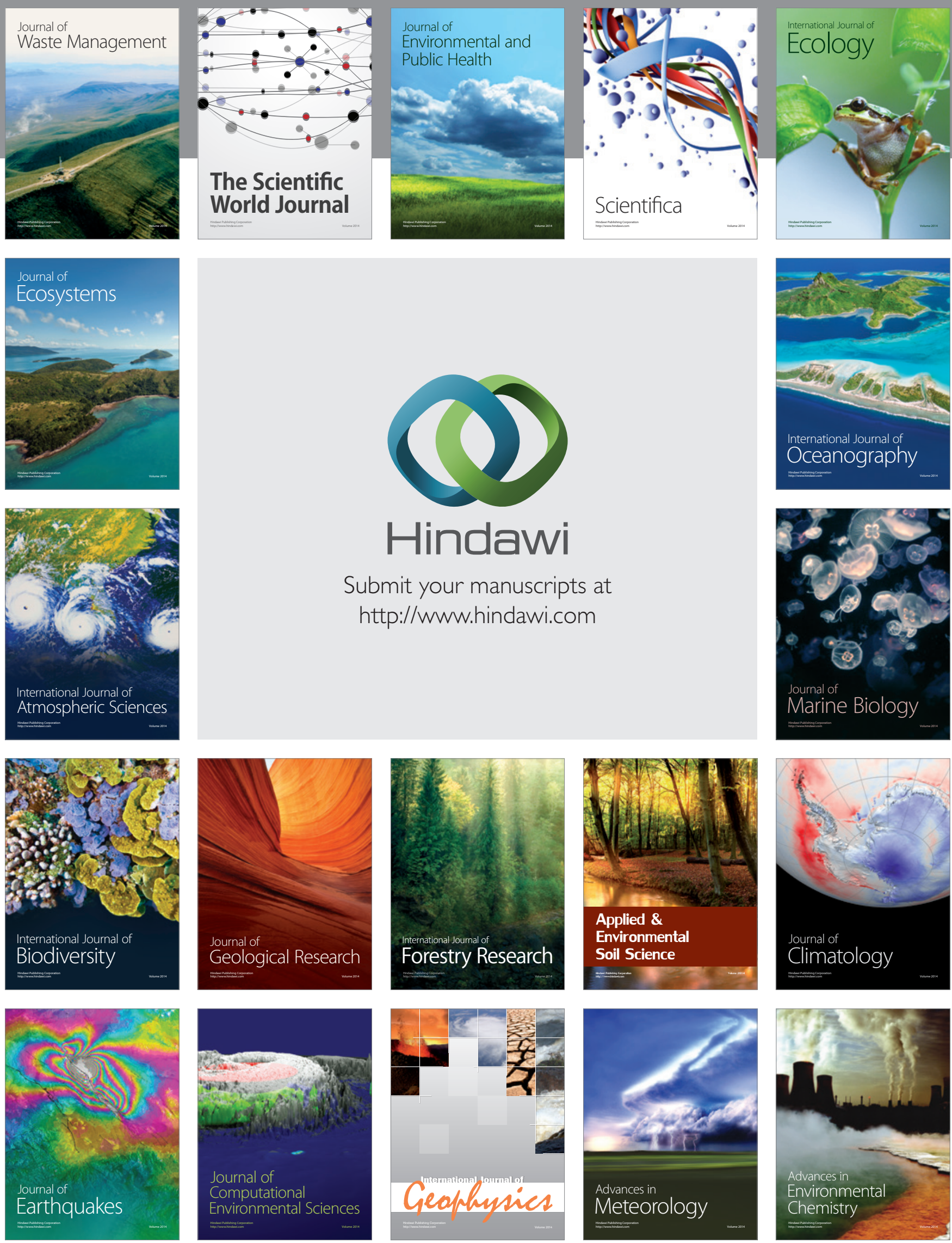